\title{
Fertilisers differentially affect facultative and obligate parasitic weeds of rice and only occasionally improve yields in infested fields
}

\author{
Dennis E. Tippe ${ }^{1,5}$, Lammert Bastiaans ${ }^{1}$, Aad van Ast ${ }^{1}$, Ibnou Dieng ${ }^{2,3}$, Mamadou Cissoko ${ }^{4}$, Juma \\ Kayeke $^{5}$, Derek W. Makokha ${ }^{6}$, Jonne Rodenburg ${ }^{7 *}$ \\ ${ }^{1}$ Centre for Crop Systems Analysis, Wageningen UR, P.O. Box 430, 6700 AK, Wageningen, the Netherlands; \\ ${ }^{2}$ Africa Rice Center (AfricaRice), 01 B.P. 2551, Bouaké, Côte d'Ivoire; ${ }^{3}$ International Institute for Tropical \\ Agriculture (IITA), PMB 5320, Oyo Road, Ibadan 200001, Nigeria; ${ }^{4}$ Department of Animal and Plant Sciences, \\ University of Sheffield, Sheffield S10 2TN, UK, ${ }^{5}$ Tanzania Agricultural Research Institute, Uyole-Center, P.O. \\ Box 400, Mbeya, Tanzania; ${ }^{6}$ Welthungerhilfe Sierra Leone Country Program, 19 Reservation Road, Kenema, \\ Sierra Leone; ${ }^{7}$ Natural Resources Institute, University of Greenwich, Central Avenue, Chatham Maritime, Kent \\ ME4 4TB, UK \\ * Corresponding Author: J. Rodenburg; E-mail: j.rodenburg@gre.ac.uk
}

\begin{abstract}
Different fertilisers were field tested to investigate whether they (1) suppress the obligate parasitic weed Striga asiatica and the facultative parasitic weed Rhamphicarpa fistulosa, and (2) favour rainfed rice yields under parasitic weed infestation. Four years of experiments were conducted in southwest Tanzania, in a S. asiatica-infested rainfed upland and a $R$. fistulosa-infested rainfed lowland field. Treatments included sole mineral (NPK or Di-Ammonium Phosphate - DAP — plus urea), organic (cattle manure or rice husk), combinations of mineral and organic fertilisers and a no-fertiliser control. Fertilisers moderately suppressed the obligate parasite $S$. asiatica, but no correlations between infestation level and soil fertility status were observed. In the lowland field, fertilisers promoted the facultative $R$. fistulosa, in particular the ones that included organic components. Plant-available phosphorus, exchangeable potassium and soil organic matter content correlated with $R$. fistulosa infestation levels. Positive fertiliser effects on yields were found in both parasitic weed infested fields, except in years with high $S$. asiatica infestation levels. Rice husks alone and rice husks or manure combined with DAP and urea increased yields and soil fertility most. We conclude that fertilisation differentially affects the obligate and facultative parasitic weeds of rice systems; obligate parasites may be slightly suppressed, but facultative parasites may even be stimulated. Meanwhile, consistent rice yield increases under parasitic weed infested conditions cannot be obtained with fertiliser application when parasitic weed infestation levels are too high.
\end{abstract}

Keywords: rainfed rice, Striga, Rhamphicarpa, soil fertility, smallholders

\section{Introduction}

Parasitic weeds are an emerging production constraint in smallholder rainfed rice environments across sub-Saharan Africa (SSA) (Rodenburg et al., 2016a). These weeds are not only competitors to crops, but also extract resources and assimilates directly from their hosts and therefore cause high crop yield losses. Two of the most popular parasitic weeds in rainfed rice systems are the well-known Striga asiatica (L.) Kuntze and the newly emerging Rhamphicarpa fistulosa (Hochst.) Benth. (Rodenburg and Johnson, 2009).

Striga asiatica is a dominant parasitic weed under rainfed upland conditions. As an obligate parasite it cannot complete its life cycle without being connected to a host plant (Westwood et al., 2011). Rice yield reductions associated with $S$. asiatica infestation have been reported to reach levels as high as $64-80 \%$ (Elliot et al., 1993). Problems with Striga spp. may be associated with crop intensification combined with poor soil fertility management. In particular low levels of soil nitrogen and phosphorus, seem to favour Striga spp. (Jamil et al., 2012; Ayongwa et al., 2006).

Rhamphicarpa fistulosa, adapted to wetlands (Hansen, 1975), is increasingly observed in rainfed lowland rice production systems (Rodenburg et al., 2015; Kabiri et al., 2015). As a facultative parasite it is capable of completing its life cycle with or without a host plant 
(Ouédraogo et al., 1999). As with Striga spp., the incidence of $R$. fistulosa seems to be associated with intensified rice cropping in the natural habitats of the species, combined with poor soil fertility management (Rodenburg et al., 2015). Rice yield losses due to R. fistulosa ranging from $30-100 \%$ have been reported (N'Cho et al., 2014), but these losses vary depending on infestation level, resistance and tolerance level of the rice variety and fertiliser application rate (Rodenburg et al., 2011, 2016b).

As incidence and severity of both parasitic weed species seem associated with low soil fertility, these could potentially be mitigated by the application of fertilisers. Several mechanisms have been proposed by which fertilisers may suppress parasitic weed infestation: (i) nutrient availability increases vigour of crop plants making them more weed competitive (Andrew et al., 2015; Blackshaw et al., 2005), (ii) high nutrient and particularly nitrogen availability reduces the amount of strigolactones released by host plant roots, which in turn reduces the germination of Striga spp. seeds (not $R$. fistulosa) and thus the infestation level (Jamil et al., 2012), (iii) a high soil organic matter stimulates soil biological activity that may expedite decay or predation of weed seeds.

There is a general lack of suitable and affordable parasitic weed control strategies adapted to smallholder rice production systems in SSA and farmers therefore primarily weed by hand or hoe which is both ineffective and laborious (Tippe et al., 2017a). Soil fertility enhancing technologies may be a valuable component in an integrated control strategy. Mineral fertilisers may be effective, but farmers usually find them too expensive. Lowering the costs of soil fertility enhancing technologies could be achieved by replacing mineral fertilisers in part or as a whole, by some of the locally available inputs. Rice husks and cattle manure are such lowcost and locally available alternatives, as farmers indicated previously (e.g. Mekuria et al. 2013; Tippe et al., 2017a), but their effects on parasitic weed infestation levels, have not been systematically tested before.

The current study was therefore set-up to investigate the following research questions: (1) Can soil fertility amendments reduce Striga asiatica /Rhamphicarpa fistulosa infestation levels in a rice crop? (2) Do rice yields benefit from soil fertility amendments when the crop is infested by parasitic weeds?

\section{Materials and Methods}

\subsection{Experimental site characterization}

Field experiments were conducted during four consecutive cropping seasons (i.e. 2012, 2013, 2014 and 2015) at Kilasilo (lowland field) and Mbako (upland field) village in Kyela district, Southwest Tanzania $\left(09^{\circ} 35^{\prime} 08^{\prime \prime} \mathrm{S}-33^{\circ} 48^{\prime} 43^{\prime \prime} \mathrm{E}\right.$ and $9^{\circ} 37^{\prime} 30^{\prime \prime} \mathrm{S}-33^{\circ} 52^{\prime} 30^{\prime \prime} \mathrm{E}$, respectively). Distance between the two experimental fields was approximately $900 \mathrm{~m}$ (Fig S1A). Experiments run from March to July (season 1 and 4) and January to June (seasons 2 and 3) and were located at around 525 meters above sea level under unimodal annual precipitation patterns. Monthly average temperatures during the cropping period ranged from 19 to $31^{\circ} \mathrm{C}$ (Kabiri et al., 2015). During the field experiments, cumulative rainfall recorded in the field was 2,170 mm (2012), 1,440 mm (2013), 2,370 mm (2014) and $552 \mathrm{~mm}$ (2015) (Fig. S1B).

Hydrologically, the soil of the upland field was characterised as free draining with a deep water table $(>1 \mathrm{~m})$ and that of the lowland field as hydromorphic and seasonally waterlogged. The lowland field was flooded variably across years, but frequently during the main growth stages of the crop (e.g. between tillering and booting).

Before the start of the experiment (March 2012), soils of both sites (upland and lowland) were sampled at three randomly dispersed positions in each replicate at $0-20 \mathrm{~cm}$ depth. Samples were mixed into one composite sample for the whole field and analysed at CropNuts laboratory in Nairobi, Kenya. Soils from both the upland and lowland field were characterized as poorly fertile, acidic with a sandy-clay-loam texture (Table 1A). Soil 
sampling was repeated just prior to the start of the fourth season (March 2015), but this time at each individual plot $(0-20 \mathrm{~cm})$ to enable assessment of fertiliser effects on soil fertility parameters (total nitrogen; available phosphorus; potassium; organic matter; $\mathrm{pH}$ ).

Table 1 Characteristics of soil (A) and organic soil amendments (B) of the experiments carried out in Kyela. Estimated macro nutrient inputs $\left(\mathrm{N}, \mathrm{P}\right.$ and $\mathrm{K}$; in $\left.\mathrm{kg} \mathrm{ha}^{-1}\right)$ by experimental soil amendment treatments $(\mathrm{C})$. $\mathrm{DAP}=$ mineral DAP fertiliser plus urea $(\mathrm{U}) ; \mathrm{NPK}=$ mineral NPK fertiliser; $\mathrm{CM}=$ Cattle manure; $\mathrm{RH}=$ Rice husks; $\mathrm{CM}+\mathrm{DAP}=$ Cattle manure and half rate of mineral DAP fertiliser plus urea; $\mathrm{RH}+\mathrm{DAP}=$ Rice husks and half rate of mineral DAP fertiliser plus urea.

\begin{tabular}{|c|c|c|}
\hline \multicolumn{3}{|c|}{ A. Basic soil characteristics from the study sites at the start of the experiments in 2012} \\
\hline Soil parameter & Upland & Lowland \\
\hline Texture (sand: silt: clay) & 63.1:11.6:25.2 & 50.2:17.6:32.1 \\
\hline $\mathrm{pH}\left(\mathrm{H}_{2} \mathrm{O}\right)$ & 5.8 & 5.4 \\
\hline Total N (in \%) ${ }^{\mathrm{a}}$ & 0.16 & 0.07 \\
\hline Available $\mathrm{P}$ (in ppm) ${ }^{\mathrm{b}}$ & 14.2 & 6.4 \\
\hline Exchangeable $\mathrm{K}$ (in ppm) ${ }^{\mathrm{b}}$ & 348.1 & 135.9 \\
\hline Soil Organic Matter (in \%) ${ }^{c}$ & 3.16 & 1.95 \\
\hline
\end{tabular}

B. Basic chemical characteristics of cattle manure $\left(90.5 \% \mathrm{DM}^{\mathrm{d}}\right)$ and rice husks $(92.1 \% \mathrm{DM})$, sampled in 2014

\begin{tabular}{lllllll}
\hline Soil amendment & $\mathrm{pH}\left(\mathrm{H}_{2} \mathrm{O}\right)$ & $\mathrm{N}\left(\text { in }^{2}\right)^{\mathrm{a}}$ & $\mathrm{P}($ in $\%) \mathrm{b}$ & $\mathrm{K}(\text { in } \%)^{\mathrm{b}}$ & $\mathrm{C}(\text { in } \%)^{\mathrm{c}}$ & $\mathrm{C}: \mathrm{N}$ \\
\hline Cattle manure $(\mathrm{CM})$ & 8.35 & 2.63 & 0.22 & 1.40 & 17.1 & 6.52 \\
Rice husks $(\mathrm{RH})$ & 5.33 & 2.94 & 0.41 & 0.71 & 43.5 & 14.8
\end{tabular}

C. Estimated inputs of N, P and K (in kg ha ${ }^{-1}$ ) per soil amendment treatment

\begin{tabular}{lllll}
\hline Treatment & Bulk quantity & $\mathrm{N}$ & $\mathrm{P}$ & $\mathrm{K}$ \\
\hline $\mathrm{DAP}+\mathrm{U}$ & 250 & 80 & 25 & 0 \\
$\mathrm{NPK}$ & 200 & 40 & 20 & 20 \\
$\mathrm{CM}$ & 10,000 & 238 & 20 & 127 \\
$\mathrm{RH}$ & 10,000 & 271 & 38 & 65 \\
$\mathrm{CM}+1 / 2(\mathrm{DAP}+\mathrm{U})$ & $10,000+125$ & 278 & 33 & 127 \\
$\mathrm{RH}+1 / 2(\mathrm{DAP}+\mathrm{U})$ & $10,000+125$ & 311 & 51 & 65 \\
\hline
\end{tabular}

${ }^{\mathrm{a}}$ Bremner and Mulvaney (1982), ${ }^{\mathrm{b}}$ Mehlich (1984), ${ }^{\mathrm{c}}$ Walkley and Black (1934), ${ }^{\mathrm{d}} \mathrm{DM}=$ dry matter.

\subsection{Plant material}

The local rice variety Supa India (O. sativa, subsp. indica) was used for both upland and lowland fields during all four cropping seasons. The growth duration of Supa India in both upland and lowland is approximately 144 days. Rice seed was obtained from Kyela District Agricultural Office. In 2012, prior to rice sowing, plots were artificially infested with parasitic weed seeds to supplement and homogenise the already existing soil seedbank in experimental plots. Both $S$. asiatica and $R$. fistulosa, seed was sourced from surrounding rice fields in Kyela during the preceding cropping season (2011).

\subsection{Field preparation}

During the first cropping season (2012), in both fields (upland and lowland), soils were ploughed using a tractor (disc plough) and, three weeks later, harrowed using an oxen-drawn harrow. Three days after harrowing, soils were prepared to a fine tilth using hand-held hoes and rakes, and debris were removed manually. Three days after levelling, plots were marked out with pegs and rice was sown two days later. In the other three cropping seasons $(2013,2014$ 2015), soil tillage was done plot by plot using hand-held hoes to maintain treatment plots. Debris were removed manually, and soil was prepared to finer tilth and levelled using hand 
hoes and rakes thereafter. In the lowland field, individual plots were surrounded by small bunds to avoid flood water cancelling out fertiliser treatments and transporting weed seeds from one plot to another.

\subsection{Experimental design and plot sizes}

In both fields, a single factor experiment, composed of seven soil fertility levels, was laid out in a Randomized Complete Block Design in five replicates, arriving at a total of 35 plots. Randomization was done once, prior to the first season, and the resulting allocation of fertility treatments to plots were maintained throughout the four years of experimentation. Each plot (3 $\mathrm{m} \times 4 \mathrm{~m}$ ) consisted of 15 rows of 20 hills each, with a sowing distance of $0.2 \mathrm{~m} \times 0.2 \mathrm{~m}$ between hills and rows. The outer two rows were used as border rows, leaving an observation area of 176 hills.

\subsection{Soil fertility treatments}

Seven soil fertility treatments were tested: (1) A 'no-fertiliser' (control), (2) DAP fertiliser plus urea in locally recommended rates, (3) NPK fertiliser in locally recommended rates, (4) Cattle manure, (5) Rice husks, (6) Cattle manure and half the recommended rate of DAP plus urea, (7) Rice husks and half the recommended rate of DAP plus urea.

Recommendations by the local District Agricultural Office (supported by the National Agricultural Research System) prescribe DAP 18:46:0 ( $\left.: \mathrm{P}_{2} \mathrm{O}_{5}: \mathrm{K}_{2} \mathrm{O}\right)$ to be applied at a rate of $125 \mathrm{~kg} \mathrm{ha}^{-1}\left(150 \mathrm{~g}\right.$ per plot) at planting and urea $(46 \% \mathrm{~N})$ at a rate of $125 \mathrm{~kg} \mathrm{ha}^{-1}(150 \mathrm{~g}$ per plot) at 70 Days After Sowing (DAS). Local recommendations prescribe NPK 20:10:10 (N:P:K) to be applied at a rate of $200 \mathrm{~kg} \mathrm{ha}^{-1}$ in 2 splits, whereby the first split was applied at 21 DAS (140.3 g per plot) while the second split was applied at 70 DAS (99.7 g per plot). Cattle manure as well as fine rice husks derived from the second chamber of the mill, whether alone or in combination with DAP and urea, were applied at a rate of 10 tons ha- $\mathrm{ha}^{-1}(12 \mathrm{~kg}$ per plot). Both organic fertilisers were thoroughly mixed with the topsoil $(0-20 \mathrm{~cm})$ at 3 days before sowing (and before additional parasitic weed seed infestation in season 1). In plots following the combined organic and mineral fertiliser treatments, both types were applied by the same methods and at the same times as described for mineral-only (DAP and urea) and organic-only treatments. Samples of organic soil amendments were taken in 2014 and analysed for their chemical composition in the CropNuts laboratory in Nairobi, Kenya (Table 1B and C).

\subsection{Crop establishment and management}

For the $S$. asiatica experiment in the upland field, the aforementioned supplemental seed infestation at the start of the experiment in 2012 was only done in a central area of the plots, encompassing 9 hills, at a rate of $0.463 \mathrm{~g} \mathrm{~m}^{-2}\left(1 \mathrm{~g}\right.$ per plot area of $\left.2.16 \mathrm{~m}^{2}\right)$. Supplemental infestation with $R$. fistulosa seed in the lowland was done in the same year at a density of approximately $1 \mathrm{~g}$ of seed $\mathrm{m}^{-2}$ for the entire plot $(3 \mathrm{~m} \times 4 \mathrm{~m})$. Prior to application, parasitic weed seeds were mixed with approximately $20 \mathrm{ml}$ of white sand per plot. The $S$. asiatica seed - sand mixture was incorporated in the upper $5-10 \mathrm{~cm}$ of the soil, using hand-held hoes and rakes. The $R$. fistulosa seed - sand mixture was spread evenly on the plot surface at rice sowing, because of the light requirement for seed germination of this species (Kabiri et al., 2016). Before the supplemental infestation, the implication of this approach and restoration strategies to apply after the experiment, were clearly discussed with the farmers owning the fields. Artificial infestations were not conducted in the next years, as this would cancel out potential inherent differences in parasitic weed seed production between treatments.

Rice was drill seeded one day after supplemental parasitic weed seed infestation in season 1 (between $2^{\text {nd }}$ and $5^{\text {th }}$ March, 2012), or after seedbed preparation in season 2, 3 (between $24^{\text {th }}$ and $30^{\text {th }}$ January, 2013 and 2014) and 4 (between $4^{\text {th }}$ and $5^{\text {th }}$ March, 2015). Soil in each 
planting hole was mixed with $1 \mathrm{~g}$ of an insecticide Furadan ${ }^{\circledR}$. Five to six seeds per hill were directly sown at a depth of 2-3 $\mathrm{cm}$ below the soil surface and thinned or gap-filled at approximately 21 DAS to three plants per hill. The trials were regularly hand weeded to remove all weeds other than parasitic weeds. Rice fields were sprayed twice within two weeks after rice tiller initiation and then four weeks later with an insecticide based on Chlorpyrifos with the trade name Dursban ${ }^{\circledR}$, to control potential insect vectors of viral diseases, especially Rice Yellow Mottle virus which is endemic in Kyela.

\subsection{Measurements and observations}

The number of parasitic weed plants growing in the net plot area was counted approximately once a month until rice harvest. These counts were used to assess the maximum number of parasitic weed plants in each plot, a measure for infestation level (Rodenburg et al., 2017). The above-ground parts of parasitic weeds were harvested at rice harvesting time and oven-dried at $70^{\circ} \mathrm{C}$ for 48 hours for biomass assessment, another measure for infestation level (Rodenburg et al., 2017; 2016b).

Upon maturity, rice panicles from all plants growing within the net plot area were cut at the senescence ring and placed in cotton bags. Rice panicles were air-dried for two weeks, threshed and winnowed to separate filled rice grains from chaff and empty grains. Filled grain weight was determined and grain moisture content was measured simultaneously using a digital grain moisture meter of SATAKE (Model SS-7) to convert all grain weights to a standard (14\%) moisture content.

\subsection{Statistical analyses}

Before analyses, data on parasitic weed numbers (NSmax or NRmax; plants $\mathrm{m}^{-2}$ ), parasitic weed biomass dry weight ( $S D W$ or $R D W ; \mathrm{g} \mathrm{m}^{-2}$ — with ' $\mathrm{S}$ ' for Striga and 'R' for Rhamphicarpa) and rice grain yield (GDW; $\mathrm{t} \mathrm{ha}^{-1}$ ) were checked for homoscedasticity (Sokal and Rohlf, 1995). Thereafter, data were analysed using a generalized linear mixed model (McCullagh and Nelder, 1989) under the assumption of a Poisson distribution for NSmax and NRmax and a linear mixed model for SDW, RDW, GDW. First, a log-likelihood ratio test was performed for the homogeneity of variance and, when the variance was not constant, the heterogeneity of the variances was considered.

Significance of Year $\times$ Fertility interaction effects were tested for all parameters. Where such two-way interaction effects were observed, a model for each year (2012, 2013, 2014 and 2015) was fitted separately, where Fertility was considered as fixed factor and Replicate as random factor. For each parameter, least-square means (LS-Means) of Fertility were computed when appropriate. For parameters for which there was a significant effect, ANOVAs were followed by a comparison of means using Tukey's honest significant difference test. Pearson correlation analyses were conducted to assess correlations between soil parameters, parasite infestation levels and rice yields.

All statistical analyses were performed with R software, Version 3.6.1 (R Core Team, 2019) using the lme4 package (Bates et al., 2015) for the ANOVA models, the lsmeans package (Lenth, 2016) for the LS-Means estimation and the multcomp package (Hothorn et al., 2008) for the Tukey multiple comparisons of means and the Hmisc package (Harrell Jr et al., 2019) for the correlation analyses.

\section{Results}

\subsection{Upland}

In the upland field experiment with $S$. asiatica, significant Year $\times$ Fertiliser interaction effects were observed on maximum $S$. asiatica number (NSmax; $P<0.0001)$, $S$. asiatica biomass $(S D W$; $P=0.027)$ and rice grain yield $(G D W ; P=0.0005)$ (Table S1). 


\subsubsection{Striga asiatica number and biomass}

Parasite infestation levels were significantly higher in 2012 and 2013 (means: 102 and 61 plants $\mathrm{m}^{-2}$, respectively) than in 2014 and 2015 (means: 2.0 and 0.3 plants $\mathrm{m}^{-2}$, respectively). As a result, $S$. asiatica biomass $(S D W)$ was only determined in the first two years.

Analysed per year, significant Fertiliser effects on maximum $S$. asiatica numbers (NSmax) were observed in 2012, $2013(P<0.0001)$ and $2014(P=0.0038)$ (Table S1). No significant effect of Fertiliser was observed on $S$. asiatica numbers in 2015. Significant Fertiliser main effects on aboveground $S$. asiatica biomass dry weight $(S D W)$ were only found in $2012(P=0.0198)$.

The relative ranking of fertiliser treatments based on their effects on $S$. asiatica numbers (NSmax) varied across years (Fig. 1). Initially, in 2012, the treatments combining organic with inorganic fertilisers resulted in relatively high parasite numbers. In the following years, these treatments consistently resulted in the lowest parasite numbers. For the no-fertiliser control treatment the opposite trend was observed; whereas in the first year (2012) the mean S. asiatica number following the control treatment was amongst the lowest, it was amongst the highest in both 2013 and 2014. Striga asiatica biomass (2012 and 2013) showed less differentiation between fertiliser treatments (Table 2). In 2012 no significant differences between treatment means were observed. In 2013, the combined organic and mineral fertiliser treatments $(\mathrm{CM}+\mathrm{DAP}$ and $\mathrm{RH}+\mathrm{DAP})$ resulted in significant lower $S$. asiatica biomass than NPK or sole rice husk application.

Table 2. Total aboveground $S$. asiatica dry weight $\left(S D W, \mathrm{~g} \mathrm{~m}^{-2}\right)$, as affected by Fertiliser treatments during the first two cropping seasons (2012-2013) in the rainfed upland rice field in Kyela, Tanzania. During 2014 and 2015 seasons, the parasite biomass was not recorded as there were not enough $S$. asiatica plants at the end of the season. None $=$ no fertiliser; $\mathrm{NPK}=$ mineral NPK fertiliser; $\mathrm{DAP}=$ mineral DAP fertiliser plus urea; $\mathrm{CM}=\mathrm{Cattle}$ manure; $\mathrm{RH}=$ Rice husks; $\mathrm{CM}+\mathrm{DAP}=\mathrm{Cattle}$ manure and half rate of mineral DAP fertiliser plus urea; $\mathrm{RH}+\mathrm{DAP}=$ Rice husks and half rate of mineral DAP fertiliser plus urea.

\begin{tabular}{lrrlr}
\hline Fertiliser & 2012 & 2013 & Mean \\
\hline None & 10.70 & 33.91 & abc & 22.31 \\
NPK & 7.64 & 40.87 & ab & 24.26 \\
DAP & 9.46 & 31.63 & abc & 20.55 \\
CM & 14.29 & 30.60 & bc & 22.45 \\
RH & 11.91 & 41.37 & $\mathrm{a}$ & 26.64 \\
CM+DAP & 17.06 & 25.80 & $\mathrm{c}$ & 21.43 \\
RH+DAP & 12.69 & 25.56 & $\mathrm{c}$ & 19.13 \\
Mean & 11.97 & 32.82 & &
\end{tabular}

Within the Fertiliser treatments, means within the same year, followed by the same letter are not significantly different according to Tukey's honest significant difference test at $P<0.05$. Absence of letters indicate differences between means were not significant. 


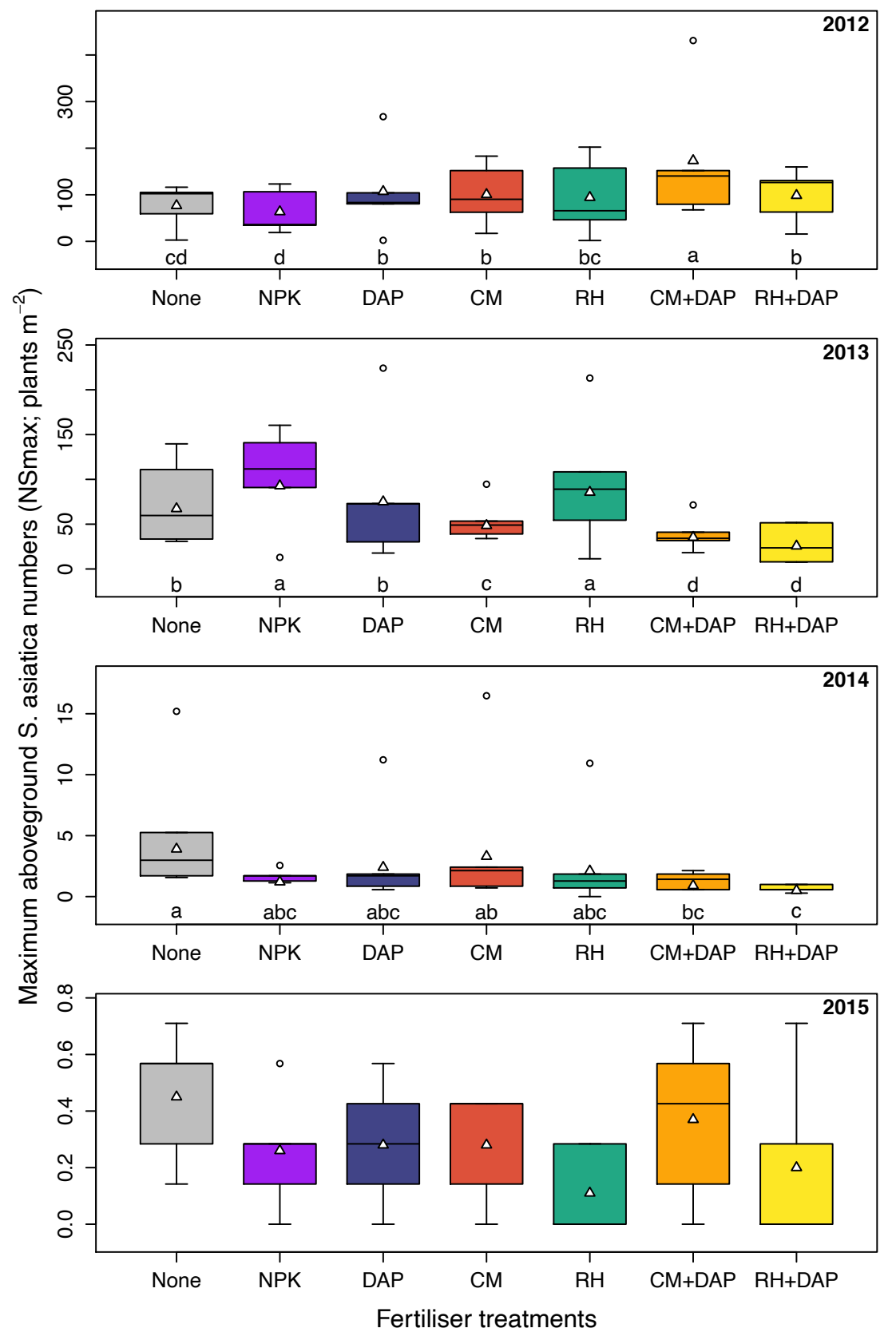

Figure 1. Box-whisker plots of maximum aboveground $S$. asiatica numbers (NSmax, plants $\mathrm{m}^{-2}$ ), as affected by Fertiliser treatments during four cropping seasons (2012-2015) in the rainfed upland rice field in Kyela, Tanzania. Within a year, treatment means (indicated by white triangles) with the same letter are not significantly different according to Tukey's honest significant difference test $(P<0.0001)$. No significant treatment effects were observed in 2015. None $=$ no fertiliser; $\mathrm{NPK}=$ mineral $\mathrm{NPK}$ fertiliser; $\mathrm{DAP}=$ mineral DAP fertiliser plus urea; $\mathrm{CM}=\mathrm{Cattle}$ manure; $\mathrm{RH}=$ Rice husks; $\mathrm{CM}+\mathrm{DAP}=$ Cattle manure and half rate of mineral DAP fertiliser plus urea; $\mathrm{RH}+\mathrm{DAP}=$ Rice husks and half rate of mineral DAP fertiliser plus urea.

\subsubsection{Upland rice grain yield}

A significant Fertiliser by Year interaction $(P=0.0005)$ effect on rice grain yield across years was observed (Table S1). Analysed per individual year, showed significant Fertiliser effects on rice grain yields $(G D W)$ in 2014 and 2015. In 2014, all fertiliser treatments resulted in significantly $(P<0.0001)$ higher grain yields compared to the no-fertiliser control, while no differences between fertiliser treatments were observed (Fig. 2). In 2015, rice husks with or without DAP and cattle manure with or without DAP resulted in a significant higher $G D W$ compared to the control treatment. The mineral fertiliser treatments NPK and DAP held 
intermediate positions. Significant negative correlations were observed between maximum $S$. asiatica numbers (NSmax) and rice grain dry weights in 2012, 2013 and 2014 (Fig. 3). Only in 2015, when parasite numbers were low, this correlation was not significant.
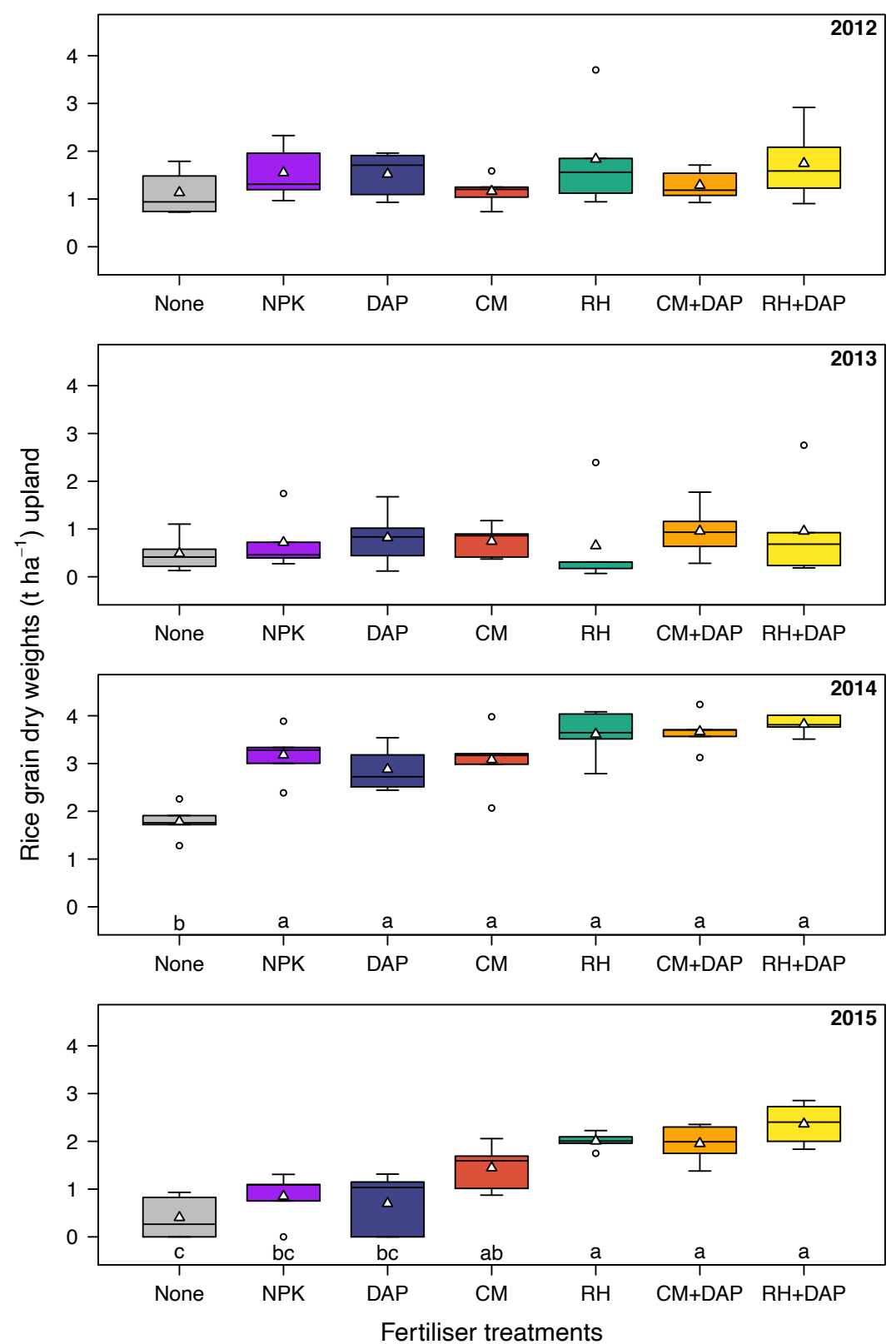

Figure 2. Box-whisker plots of rice grain yield $\left(G D W, \mathrm{t} \mathrm{ha}^{-1}\right)$, as affected by Fertiliser treatments during four cropping seasons (2012-2015) in the rainfed upland rice field in Kyela, Tanzania. Within a year, treatment means (indicated by white triangles) with the same letter are not significantly different according to Tukey's honest significant difference test $(P<0.05)$. No significant treatment effects were observed in 2012 and 2013. None $=$ no fertiliser; $\mathrm{NPK}=$ mineral $\mathrm{NPK}$ fertiliser; $\mathrm{DAP}=$ mineral $\mathrm{DAP}$ fertiliser plus urea; $\mathrm{CM}=$ Cattle manure; $\mathrm{RH}=$ Rice husks; $\mathrm{CM}+\mathrm{DAP}=$ Cattle manure and half rate of mineral $\mathrm{DAP}$ fertiliser plus urea; $\mathrm{RH}+\mathrm{DAP}=$ Rice husks and half rate of mineral DAP fertiliser plus urea. 

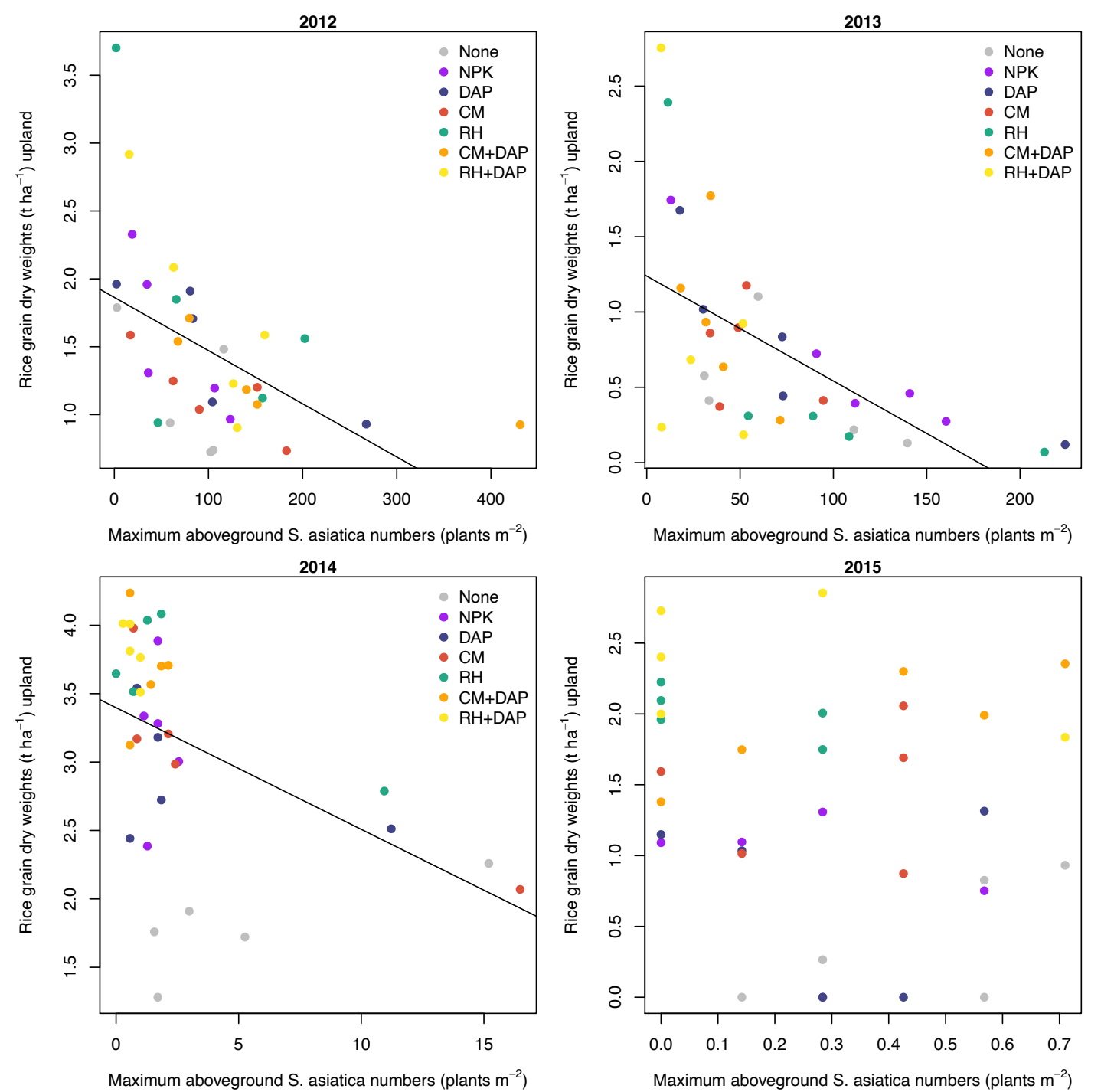

Figure 3. Relation between maximum aboveground Striga asiatica numbers (plants $\mathrm{m}^{-2}$ ) and rice grain dry weights $\left(\mathrm{t} \mathrm{ha} \mathrm{A}^{-1}\right)$ in the upland field for all four years $(2012: \mathrm{r}=-0.52 * * ; 2013: \mathrm{r}=-0.59 * * * ; 2014: \mathrm{r}=-0.47 * * ; 2015: \mathrm{r}=-0.18 \mathrm{~ns}$; with *** $\mathrm{P}<0.0001$ and $* * \mathrm{P}<0.001)$.

\subsection{Lowland}

A significant $(P<0.0001)$ Year $\times$ Fertiliser interaction effect was observed on $R$. fistulosa maximum plant number (NRmax; plants $\left.\mathrm{m}^{-2}\right)$, R. fistulosa biomass dry weights $(R D W)$ and rice grain yield $\left(G D W ; \mathrm{t} \mathrm{ha}^{-1}\right)$ (Table $\left.\mathrm{S} 2\right)$. When analysed per year, significant Fertiliser effects were found on NRmax and on GDW in all years. Significant Fertiliser effects on $R$. fistulosa dry weights were observed in 2012 and 2015 but not in 2013 and 2014.

\subsubsection{Rhamphicarpa fistulosa number and biomass}

Both in terms of number and biomass dry weight, the $R$. fistulosa infestation level was highest in 2012. In that year, the highest $R$. fistulosa plant number (NRmax) were observed following fertiliser treatments with organic components, although no significant differences were observed between rice husk combined with DAP and DAP applied alone, both showing intermediate parasite numbers (Fig. 4). The lowest numbers were observed in plots that received sole NPK or no fertiliser.

In 2013, a differentiation was observed between the fertiliser treatments that included organic components and the other treatments. Parasite numbers were generally higher following 
organic fertiliser treatments. The highest $R$. fistulosa infestation level was observed after application of cattle manure, significantly higher than the no-fertiliser, NPK or DAP alone treatments. The lowest parasite numbers were observed following sole NPK, significantly lower than cattle manure and rice husks combined with DAP. In 2014, this differentiation was even more pronounced; all fertiliser treatments that included organic components resulted in significant higher $R$. fistulosa numbers than the no-fertiliser control or sole NPK or DAP treatments. In 2015, only the application of cattle manure with or without DAP resulted in significant higher $R$. fistulosa numbers than the no-fertiliser control treatment. Plots receiving rice husks with DAP had the lowest mean parasite infestation level followed by the no-fertiliser control treatment. Plots receiving sole rice husks, NPK, DAP were intermediate.

Fertiliser treatment effects on $R$. fistulosa biomass dry weights $(R D W)$ were somewhat variable across years (Table 3). In 2012, the fertiliser treatments with organic components resulted in significant higher parasite dry weights than the no-fertiliser control and sole NPK treatments, while DAP had intermediate levels. In 2015 the lowest parasite biomass was again observed in the no-fertiliser control plots followed by sole DAP. These two treatments resulted in significant lower biomass than application of NPK, which recorded the highest biomass dry weight level. Application of rice husks or cattle manure combined with DAP resulted in significant higher parasite biomass than the no-fertiliser control. Other treatments were intermediate.

Table 3. Total above-ground $R$. fistulosa dry weight $\left(R D W ; \mathrm{g} \mathrm{m}^{-2}\right)$, as affected by Fertiliser treatments during four cropping seasons (2012-2015) in the rainfed lowland rice field in Kyela, Tanzania. None $=$ no fertiliser; DAP= mineral DAP fertiliser plus urea; $\mathrm{NPK}=$ mineral NPK fertiliser; $\mathrm{CM}=$ Cattle manure; $\mathrm{RH}=$ Rice husks; $\mathrm{CM}+\mathrm{DAP}=$ Cattle manure and half rate of mineral DAP fertiliser plus urea; $\mathrm{RH}+\mathrm{DAP}=$ Rice husks and half rate of mineral DAP fertiliser plus urea.

\begin{tabular}{lccccccc}
\hline Fertiliser & 2012 & & 2013 & 2014 & 2015 & Mean \\
\hline None & 82.1 & $\mathrm{c}$ & 38.2 & 18.4 & 23.1 & $\mathrm{c}$ & 40.4 \\
NPK & 92.3 & $\mathrm{bc}$ & 36.4 & 6.4 & 113.4 & $\mathrm{a}$ & 62.1 \\
DAP & 202.9 & $\mathrm{ab}$ & 9.3 & 13.2 & 40.4 & $\mathrm{bc}$ & 66.4 \\
CM & 256.3 & $\mathrm{a}$ & 45.7 & 38.0 & 70.2 & $\mathrm{abc}$ & 102.5 \\
RH & 232.3 & $\mathrm{a}$ & 25.6 & 41.5 & 93.8 & $\mathrm{ab}$ & 98.3 \\
CM+DAP & 269.4 & $\mathrm{a}$ & 23.8 & 37.2 & 98.9 & $\mathrm{ab}$ & 107.3 \\
RH+DAP & 228.4 & $\mathrm{a}$ & 33.0 & 24.5 & 54.3 & $\mathrm{abc}$ & 85.1 \\
Mean & 194.8 & & 30.3 & 25.6 & 70.6 & & \\
\hline
\end{tabular}

Means within the same year, followed by the same letter are not significantly different according to Tukey's honest significant difference test at $P<0.05$. Absence of letters indicate differences between means were not significant. 


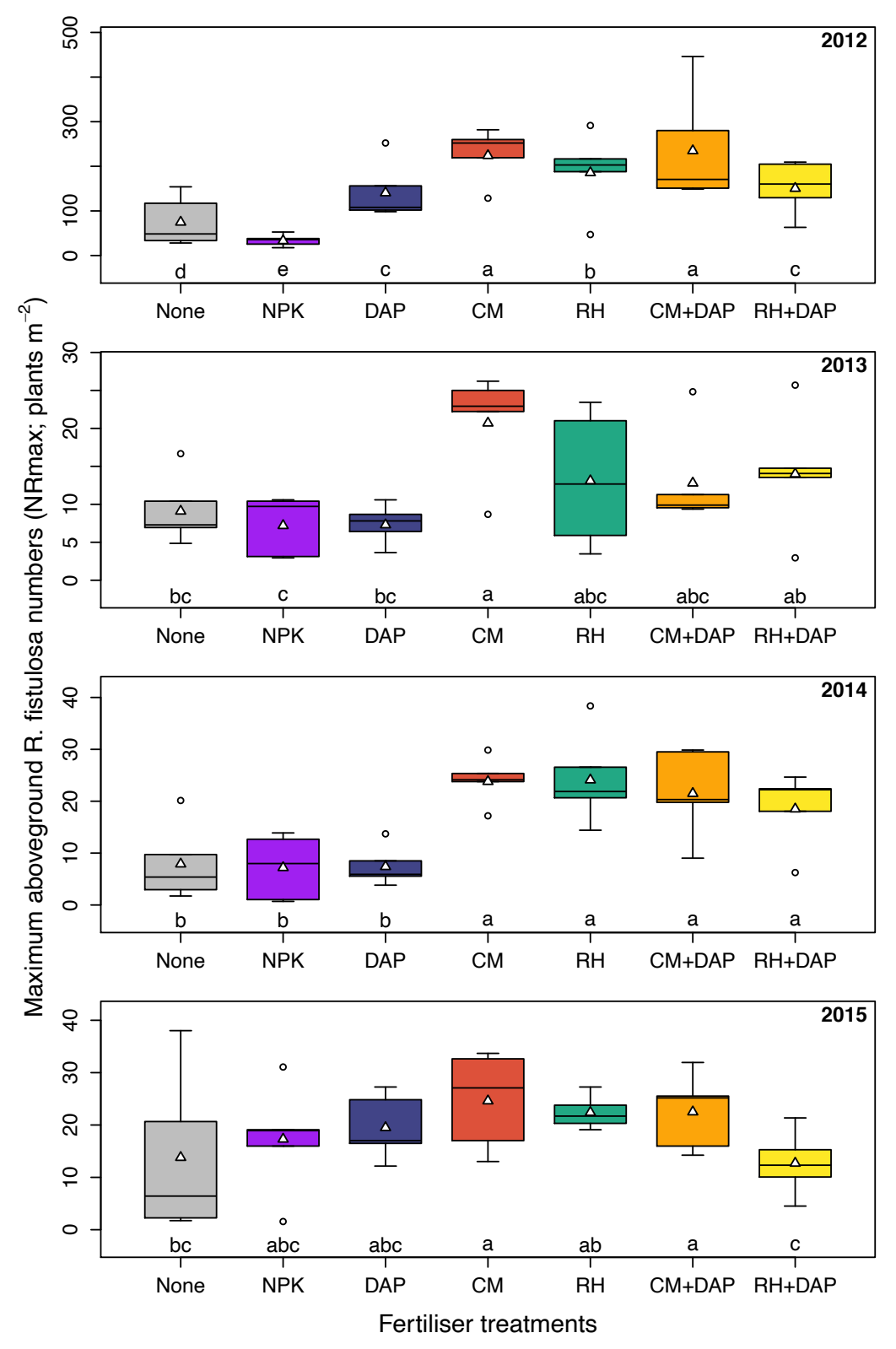

Figure 4. Box-whisker plots of maximum R. fistulosa plant number (NRmax; plants $\mathrm{m}^{-2}$ ), as affected by Fertiliser treatments. Data were collected in the rainfed lowland rice field in Kyela, Tanzania. Within a year, treatment means (indicated by white triangles) with the same letter are not significantly different according to Tukey's honest significant difference test $(P<0.0001$ in 2012, 2014 and 2015; $P<0.01$ in 2013). None $=$ no fertiliser; NPK= mineral $\mathrm{NPK}$ fertiliser; $\mathrm{DAP}=$ mineral DAP fertiliser plus urea; $\mathrm{CM}=$ Cattle manure; $\mathrm{RH}=$ Rice husks; $\mathrm{CM}+\mathrm{DAP}=\mathrm{Cattle}$ manure and half rate of mineral DAP fertiliser plus urea; $\mathrm{RH}+\mathrm{DAP}=$ Rice husks and half rate of mineral DAP fertiliser plus urea.

\subsubsection{Lowland rice grain yield}

In 2012, following the very high $R$. fistulosa infestation levels, rice yields in the lowland field were significantly lower than in other years (Table S2; Fig. 5). Fertilisers had a significant effect on rice yields, but improvements were only marginal. Highest grain yields in that year were obtained with the fertiliser treatment that combined rice husks with DAP, despite relatively intermediate to high parasite numbers, and lowest yields were observed with cattle manure (with or without DAP), with parasite numbers that were comparable to those obtained with the 
rice husk treatments (Fig. 6). Application of NPK combined relatively low parasite numbers with relatively intermediate to high rice grain yields (Fig. 6).

In following years, yields were always significantly higher when fertilisers were applied than the no-fertiliser control treatments, except for NPK in 2013, cattle manure in 2014 and NPK or cattle manure in 2015 (Fig. 5). The DAP and the rice husks combined with DAP treatments consistently resulted in the highest rice grain yields in 2013, 2014 and 2015. In 2013 and 2014, rice husks alone and cattle manure with DAP resulted in comparably high rice yields as these two best treatments. Only in 2012, the year with the highest parasite infestation levels, a significant negative correlation was observed between $R$. fistulosa numbers and rice grain yields (Fig. 6).
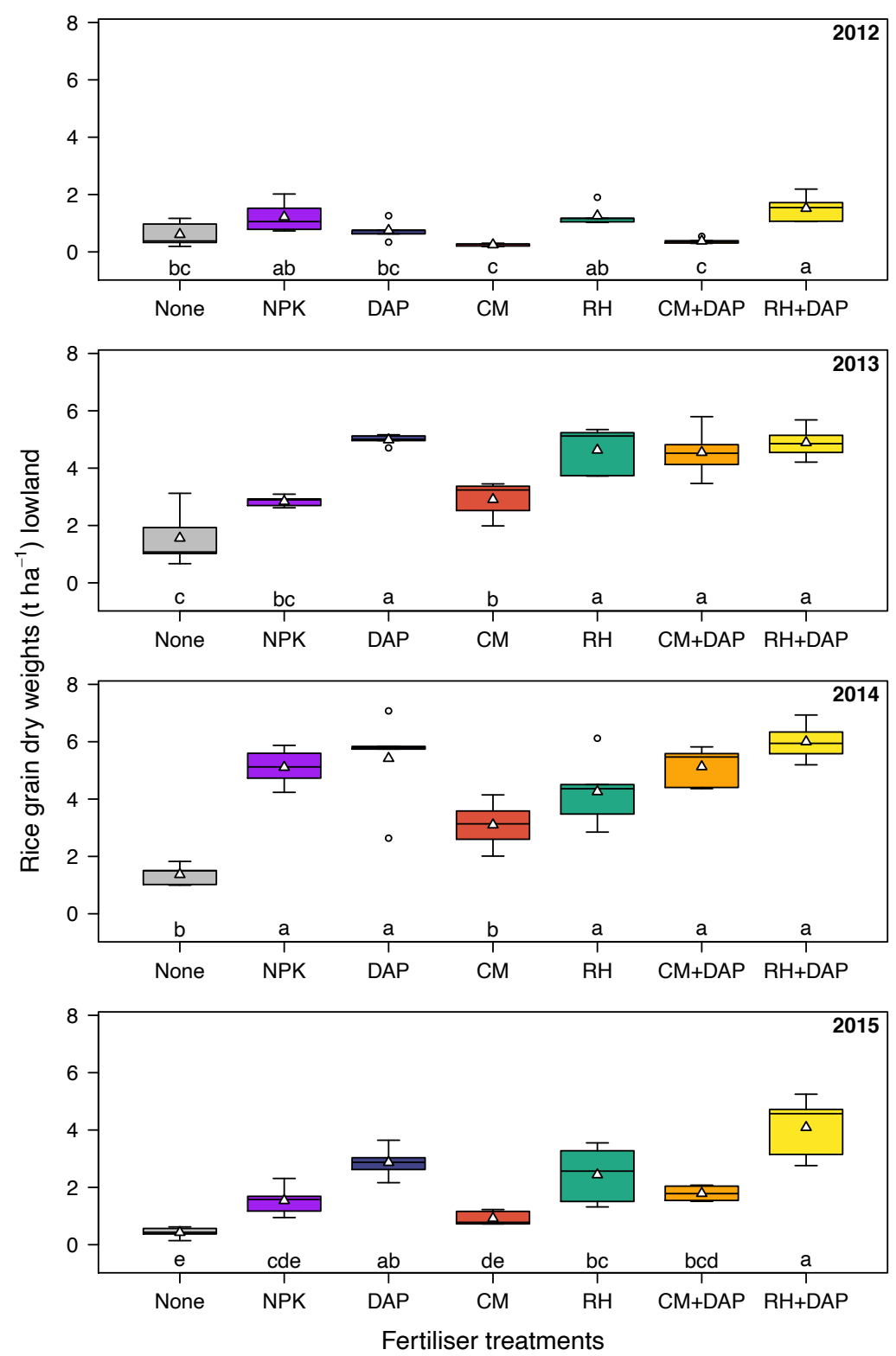

Figure 5. Rice grain yield $\left(G D W ; \mathrm{t} \mathrm{ha}^{-1}\right)$ as affected by Fertiliser treatments in the rainfed lowland rice field in Kyela, Tanzania. Within a year, treatment means (indicated by white triangles) with the same letter are not significantly different according to Tukey's honest significant difference test $(P<0.0001$ in 2012 and $2013 ; P<0.01$ in 2014; $P<0.001$ in 2015). None= no fertiliser; NPK= mineral NPK fertiliser; $\mathrm{DAP}=$ mineral DAP fertiliser plus urea; $\mathrm{CM}=$ Cattle manure; $\mathrm{RH}=$ Rice husks; $\mathrm{CM}+\mathrm{DAP}=$ Cattle manure and half rate of mineral DAP fertiliser plus urea; $\mathrm{RH}+\mathrm{DAP}=$ Rice husks and half rate of mineral DAP fertiliser plus urea. 

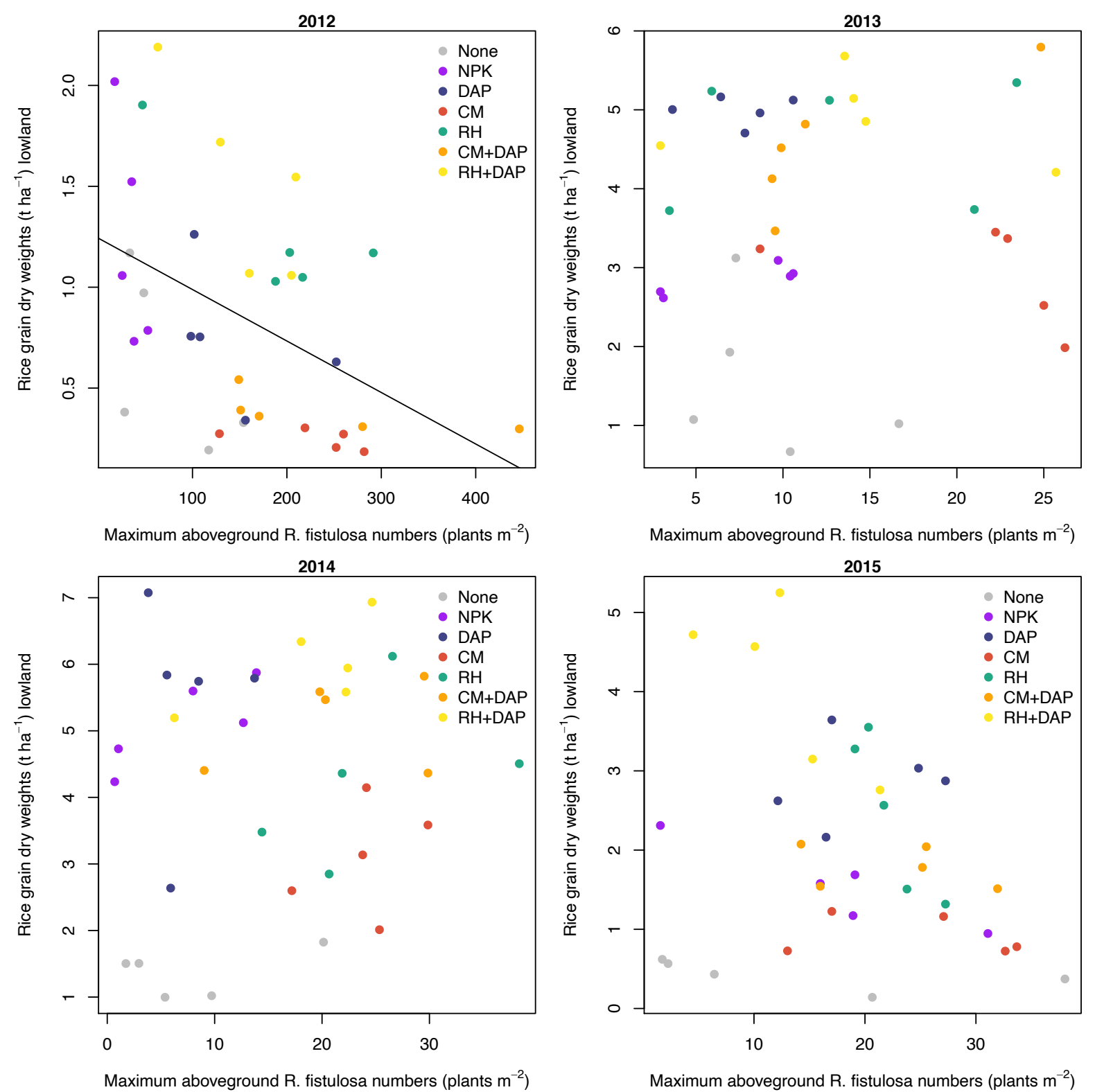

Figure 6. Relation between maximum Rhamphicarpa fistulosa numbers (plants $\mathrm{m}^{-2}$ ) and rice grain dry weights $(\mathrm{t}$ $\left.\mathrm{ha}^{-1}\right)$ in the lowland field for all four years (2012: $\mathrm{r}=-0.44^{* *} ; 2013: \mathrm{r}=0.04 \mathrm{~ns} ; 2014: \mathrm{r}=0.16 \mathrm{~ns} ; 2015: \mathrm{r}=-0.26 \mathrm{~ns}$; with ** $\mathrm{P}<0.001)$.

\subsection{Soil fertility}

Prior to the last season (2015), the status of important soil fertility parameters -i.e. total nitrogen, available phosphorus, potassium, soil organic matter and $\mathrm{pH}$ - were assessed.

\subsubsection{Soil fertility in S. asiatica-infested upland field}

After three seasons, fertiliser treatments caused significant changes in soil available phosphorus ( $\mathrm{P} ; P=0.0247)$, exchangeable potassium $(\mathrm{K} ; P<0.001)$ and $\mathrm{pH}(P<0.001)$ in the upland field (Table S3). No significant fertiliser effects on soil total nitrogen ( $\mathrm{N}$ total) and soil organic matter content were observed.

Compared to the no-fertiliser control treatment, available phosphorus increased significantly following applications of rice husks alone or in combination with DAP (Fig. S2). Potassium increased significantly following application of rice husks alone or cattle manure with or without additional DAP. Potassium was lowest with the sole DAP treatments, followed 
by the no-fertiliser control treatments, and intermediate with NPK and rice husks combined with DAP. Despite significant differences, soil $\mathrm{pH}$ changes following fertiliser treatments were only minor, ranging between 5.12 (with DAP) and 5.57 (CM), and therefore not shown. Soil fertility parameters did not correlate with $S$. asiatica plant numbers in 2014 or 2015 (Table S4). Significant positive correlations with rice grain dry weights were observed with soil organic matter and total nitrogen in 2014 (Table S4) and with all soil parameters in 2015 (Table S4; Figure 7).
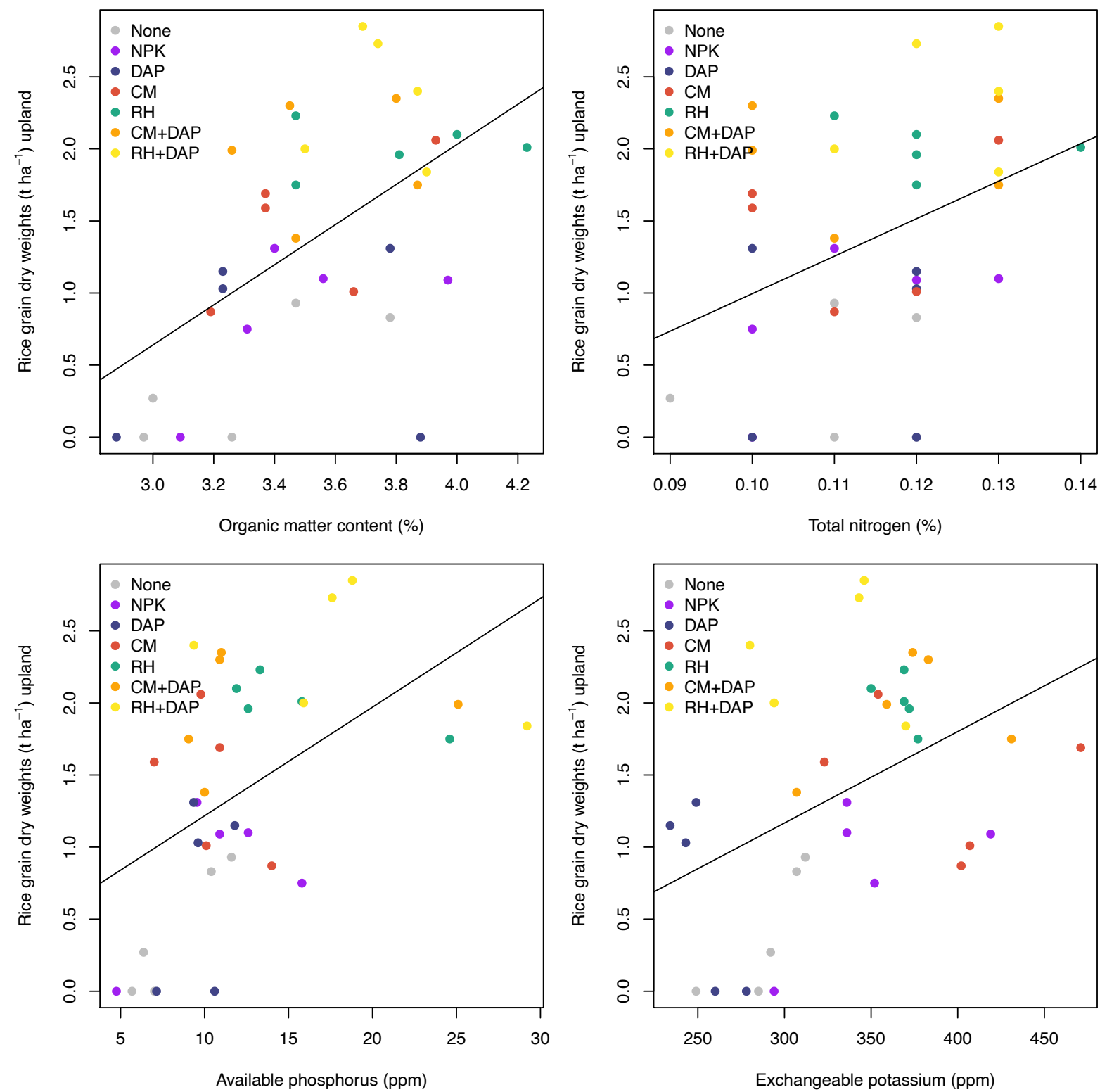

Figure 7. Relation between soil fertility parameters $\left(\mathrm{N}_{\text {Total }}[\%] ; \mathrm{P}_{\text {Avaialble }}[\mathrm{ppm}] ; \mathrm{K}_{\text {exchangeable }}[\mathrm{ppm}] ; \mathrm{SOM}[\%]\right)$ and rice grain dry weights $\left(\mathrm{t} \mathrm{ha}^{-1}\right)$ of the $S$. asiatica infested upland field in $2015\left(\mathrm{~N}_{\text {Total }}: \mathrm{r}=0.39^{*} ; \mathrm{P}_{\text {available: }} \mathrm{r}=\right.$

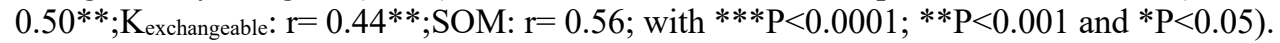



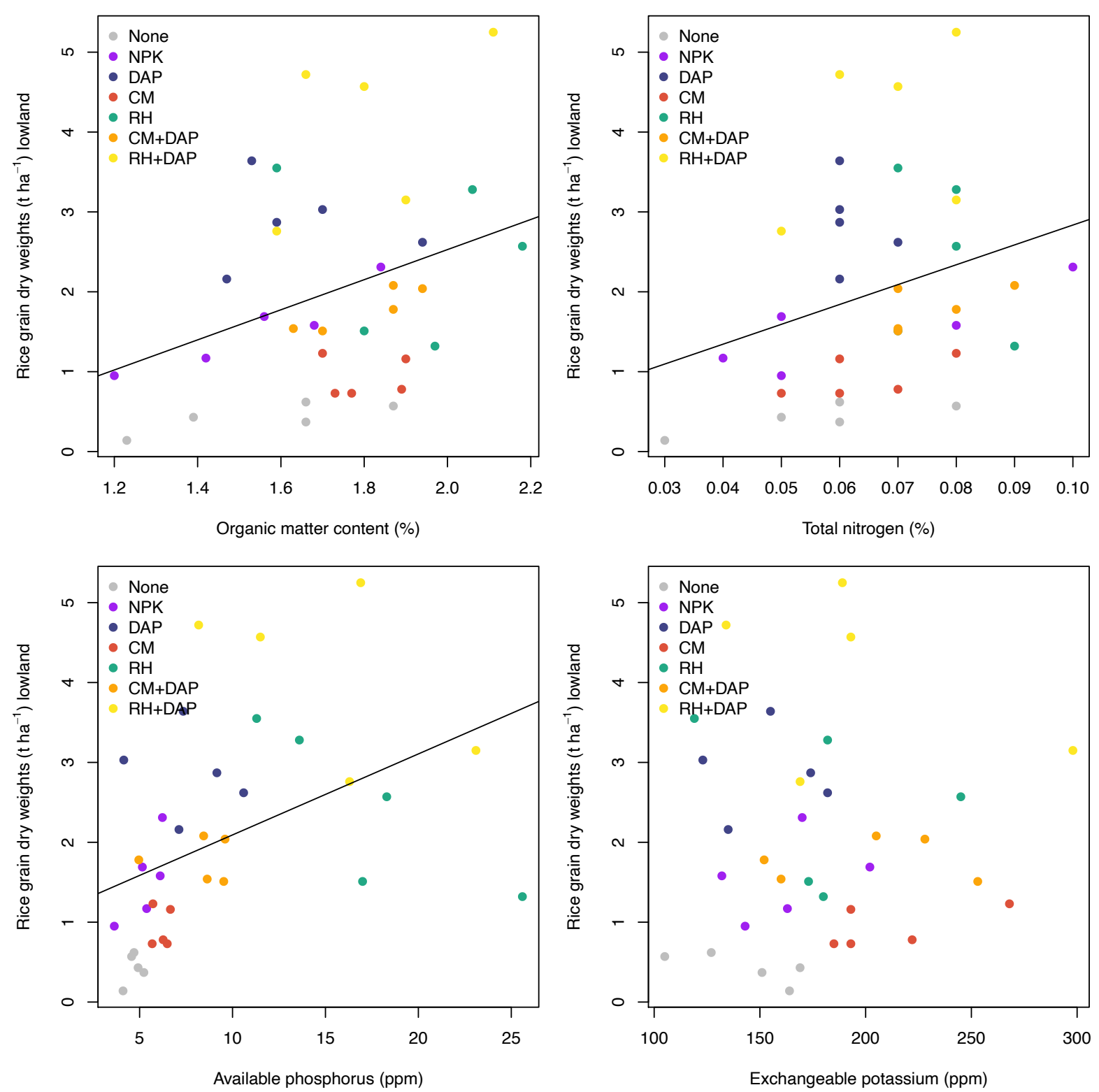

Figure 8. Relation between soil fertility parameters ( $\mathrm{N}_{\text {Total }}[\%]$; PAvailable $\left.[\mathrm{ppm}] ; \mathrm{K}_{\text {exchangeable }}[\mathrm{ppm}] ; \mathrm{SOM}[\%]\right)$ and rice grain dry weights $\left(\mathrm{t} \mathrm{ha}^{-1}\right)$ of the $R$. fistulosa infested lowland field in $2015\left(\mathrm{~N}_{\text {Total }}: \mathrm{r}=0.28 \bullet\right.$; $\mathrm{P}_{\text {Available: }} \mathrm{r}=$

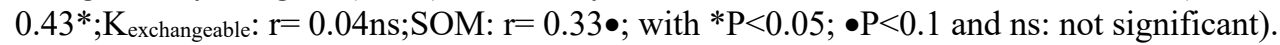

\subsubsection{Soil fertility in R. fistulosa-infested lowland field}

After three seasons, fertiliser treatments in the lowland field caused significant differences in available phosphorus ( $\left.\mathrm{P}_{\text {available}} ; P<0.001\right)$, and soil organic matter $(\mathrm{SOM} ; P=0.041)$ and marginally significant differences in potassium ( $\left.\mathrm{K}_{\text {exchangeable; }} P=0.068\right)$ and $\mathrm{pH}(P=0.078)$ (Table S3). Compared to the no-fertiliser control treatment, soil organic matter (SOM) content increased with all treatments that included an organic component (rice husk or cattle manure) but this increase was only significant for the sole rice husk treatment (Fig. S3). Application of all fertilisers that included an organic component resulted in a significant higher SOM content than those following NPK. Available phosphorus following applications of rice husks with or without DAP were significantly higher than with any other fertiliser treatments.

Rhamphicarpa fistulosa numbers positively correlated with available phosphorus $\left(\mathrm{P}_{\text {available }} ; P<0.01\right)$, exchangeable potassium $\left(\mathrm{K}_{\text {exchangeable }} P<0.001\right)$ and soil organic matter content $(\mathrm{SOM} ; P<0.01)$ in 2014 (Table S4). No correlations between soil parameters and 
parasite numbers were observed in 2015. Rice grain dry weights in the lowland field only correlated positively $(P<0.01)$ with available phosphorus in 2014 (Table S4) and 2015 (Table S4; Fig. 8). Marginally significant positive correlations between rice grain dry weights and $\operatorname{SOM}(P=0.056)$ and total nitrogen $(P=0.098)$ were observed in 2015 (Table S4; Fig. 8).

\section{Discussion}

Parasitic weeds are frequently associated with low soil fertility. Probably one of the earliest reports on this relation comes from Porteres (1948) who characterised parasitic weeds as indicators of poor or declining soil fertility of arable land: "The first appearance of Striga marks the moment when a less exiguous crop must be grown, or the land fallowed. Rhamphicarpa fistulosa is of similar significance". This suggests that fertiliser application might be an effective management strategy against parasitic weeds. This was tested under field conditions in an experiment that lasted for four years, in a rainfed upland field infested with $S$. asiatica and a rainfed lowland field infested with $R$. fistulosa. The study specifically aimed at testing soil amendments that were affordable and accessible by smallholder farmers, and focussed on two research questions: (1) Do soil fertility amendments reduce $S$. asiatica /R. fistulosa infestation in a rice crop? (2) Do rice yields benefit from soil fertility amendments when the crop is infested by parasitic weeds?

For both $S$. asiatica and $R$. fistulosa the infestation levels between years differed markedly. The same was true for parasitic biomass, though for $R$. fistulosa to a lesser extent than for $S$. asiatica. Compared to this annual variation, the differences in $S$. asiatica infestation levels brought about by the application of soil amendments were only marginal. Variation in Striga spp. numbers between years is a common phenomenon and is most likely the result of differences in rainfall distribution between years as previously suggested by Johnson et al. (1997) and Rodenburg et al. (2017). In the current study, this seems a plausible reason as well, with low S. asiatica numbers in 2014, showing an unusual wet month of April, and in 2015 with low rainfall throughout the season. Rodenburg et al. (2017) observed that climatic variation did not affect the expression of varietal resistance in rice as the variety rankings based on Striga spp. numbers showed to be rather stable across years. Contrastingly, the current study showed that fertiliser effects on S. asiatica do depend on rainfall distribution, as the ranking of the fertiliser treatments changed between years. Nevertheless, some patterns were visible. In the second and third year, soil amendments, in particular the treatments where organic and mineral fertilisers were combined, reduced $S$. asiatica numbers. This was remarkable, since in the first year these treatments resulted in higher infestation levels than the no-fertiliser control. In the fourth year, $S$. asiatica levels were so low that no conclusion could be drawn. This also explains the lack of correlation between $S$. asiatica numbers and soil fertility parameters in this year. Rice yields obtained from the upland field showed a mirror image of the $S$. asiatica infestation levels, with low yields in the years of heavy infestation and higher yields in years with lower infestation, although suboptimal rainfall also caused yields to be fairly low in the last year despite low $S$. asiatica infestation.

As with $S$. asiatica, seasonal differences in R. fistulosa have been reported before and also suggested to be related to annual rainfall distribution patterns (Kabiri et al., 2015). In the current study, the lowest $R$. fistulosa infestation levels were observed in 2013, the year with the highest early-season and lowest mid- and late-season rainfall. Fertiliser treatments that included an organic component generally resulted in increased $R$. fistulosa numbers, and this was possibly mainly caused by increased soil organic matter and available phosphorus levels. Apart from rainfall effects, observed seasonal variations in the effects of soil amendments could be the result of variations in quality of these fertilisers. Previously, Ayongwa et al. (2011) showed that in particular sub-optimal $\mathrm{N}$ rates in soil amendments could actually increase parasite numbers. While the total nutrient inputs provided by the organic fertilisers were much higher 
than those of the mineral fertilisers, an important part of these may not be readily available which may explain some of the delayed effects as well.

Pot experiments often suggest that fertiliser application is a highly effective management strategy against parasitic weeds. A great number of studies under controlled conditions showed a clear negative relation between important soil fertility parameters, such as N and P, and Striga spp. (e.g. Jamil et al., 2011; Cechin and Press, 1993). Under comparable controlled conditions of a pot experiment, also the numbers and biomass of $R$. fistulosa showed to be negatively related with fertiliser application rates (Rodenburg et al., 2011). Similarly, with Rhinanthus minor, a facultative hemi-parasite like R. fistulosa, under the semi-controlled conditions of a pot experiment, phosphorus fertilisation reduced the parasite biomass (Davies and Graves, 2000). Such findings suggest that fertiliser application could be a suitable strategy to reduce parasitic weed problems in the field.

For Striga spp., previous field studies showed that fertilisers indeed reduced infestation rates, but results were less consistent than under controlled conditions (Jamil et al., 2012). Counter-intuitive effects from N fertiliser on Striga infestation levels in the field have also been reported before, e.g. increased infestation going from 120 to $150 \mathrm{~kg} \mathrm{~N}$ ha (Showemimo et al., 2002). The current study confirms that under actual field conditions the effects of fertiliser applications on S. asiatica are less strong and consistent than under controlled conditions. It has been suggested, by Ahonsi et al. (2002), that the lack of a clear-cut relation between $\mathrm{N}$-fertiliser and Striga, in particular under field conditions, could be related to differences in activity of soil flora and fauna. They reported that when the soil microbiome was inactivated, nitrogen fertilization increased $S$. hermonthica infestation levels, but when the microbiome was active the opposite effects were observed.

For $R$. fistulosa the applicability of findings under controlled experimental conditions was not field-tested earlier. Surprisingly, here it was found that the effects on $R$. fistulosa were quite different from what was expected based on previous results under more controlled conditions by Rodenburg et al. (2011b). The application of soil amendments in the current study frequently resulted in increased $R$. fistulosa infestation levels, mostly in terms of parasite numbers. Such observed higher infestation levels following soil amendments, also seems to contradict with farm surveys by N'cho et al. (2014) who observed that $R$. fistulosa incidence in farmers' fields was negatively related to soil fertility. In the latter study by N'cho et al. (2014) the fertility status of the soils were however qualitatively based on farmer perceptions rather than soil sampling and quantitative analyses, which does not provide undeniable evidence of this causality.

Evidently, the application of soil amendments, even for an extended period of time, does not provide the silver bullet for dealing with parasitic weeds and sometimes even stimulate their presence. Fertiliser effects seem to depend not just on the type and composition of fertilisers, as earlier concluded by Hearne (2009), but also on the seasonal rainfall distribution and the type of parasitic weed. The experiments show moderate differences between the parasitic weed species: $S$. asiatica is mostly suppressed, while $R$. fistulosa is primarily promoted. Such a difference in response to a cultural control measure, albeit more strongly, was also observed for the effect of sowing time in another experiment. Late sowing of rice reduced $S$. asiatica infestation while early sowing reduced $R$. fistulosa infestation (Tippe et al., 2017a). Kabiri et al., $(2015,2016)$ previously clearly identified the differences between these two species in terms of ecology (i.e. upland vs lowland affinity) and biology (i.e. obligate vs facultative parasitism) and based on that derived the assumption that parasitic weed management strategies in rice need to be made species-specific. Interestingly, both Tippe et al. (2017a) and the current study, prove this assumption to be correct.

Rice yields were generally negatively affected by parasitic weed infestation, with stronger negative effects in years with higher infestation levels, in particular when no fertilisers were 
applied at all. Indeed, positive effects of soil amendments on rice grain yields were frequently observed. Rice husk alone and rice husk or manure combined with DAP were more successful measures to maintain rice yields above $2 \mathrm{t} \mathrm{ha}^{-1}$ under both $S$. asiatica and $R$. fistulosa-infested conditions, than sole mineral fertiliser applications. An obvious explanation for this is that these organic treatments also generally improved soil fertility better than sole mineral fertiliser applications in both environments. Clearly, the application of large quantities of these amendments in this study $\left(10 \mathrm{tha}^{-1}\right)$ resulted in much higher macro nutrient inputs compared to the sole mineral fertilisers. While the application of DAP and NPK also frequently resulted in a higher rice grain yield than that obtained following the no-fertiliser control treatment, farmers in the study area indicate that mineral fertilisers are too expensive and not reliably available on rural markets (Tippe et al., 2017b). Rice husks may therefore offer smallholder farmers with a suitable alternative to mineral fertilisers, as Mekuria et al. (2013), previously demonstrated this to be a low-cost technology to increase soil fertility and crop yields. Whether the large quantities applied in the current study would make a feasible recommendation to smallholder farmers however also depends on availability of the means to transport these organic amendments to farmers' fields, and this may vary among farms. To generate recommendations that are applicable by a wider range of farmers, the effectiveness of lower quantities of these amendments should be studied.

\section{Conclusions}

This study has shown the utility of fertiliser application in parasitic weed infested rice fields. The direction of the fertiliser effect seems to depend on the parasitic nature of the species. We have identified moderately reduced infestation rates of the obligate parasitic weed Striga asiatica, whereas fertiliser applications generally increased the numbers and biomass of the facultative parasitic weed species Rhamphicarpa fistulosa. Positive fertiliser effects on rice grain yield were less consistent under conditions of relatively high parasitic weed infestation. The effects of fertilisers were subject to variability between years, because parasitic weeds are subject to strong year effects. Fertilisers with organic components, in particular rice husks, were found to have a more pronounced effect on soil fertility and rice yields compared to fertilisers that are purely of mineral nature. Based on these findings, farmers could be advised to replace part of the inorganic fertiliser inputs by cheaper and widely available alternatives such as rice husks, to maximize rice yields, and to combine this with effective additional measures to control parasitic weeds, in particular $R$. fistulosa, to avoid that fertiliser inputs are wasted.

Acknowledgements Financial support from the Netherlands Organisation for Scientific Research through Science for Global Development (NWO-WOTRO; grant W01.65.327.00) is gratefully acknowledged. Additional support was provided by the CGIAR Research Programs Global Rice Science Partnership (GRiSP) and Climate Change, Agriculture and Food Security (CCAFS). We thank the farmers, Bernard Siwila and Dainesi Kivinga, for enabling us to conduct experiments in their field. Mwalimu K. Menza, Enos A. Onyuka, and Elifadhili Daniel are kindly acknowledged for their technical assistance during the various stages of this work. We thank Lucie Büchi of NRI for her excellent help and advice with the figures.

\section{References}

Ahonsi M.O., et al., 2002. Effects of soil pasteurisation and soil N status on severity of Striga hermonthica (Del.) Benth. in maize. Soil Biol. Biochem. 34, 1675-1681

Anderson R.L., 1991. Timing of nitrogen application affects downy brome (Bromus tectorum) growth in winter wheat. Weed Tech. 5, 582-585 
Andrew, I. K. S., Storkey, J. \& Sparkes, D. L. 2015. A review of the potential for competitive cereal cultivars as a tool in integrated weed management. Weed Res. 55, 239-248.

Ayongwa G.C., Stomph T.J., Kuyper T.W., 2011. Host-parasite dynamics of Sorghum bicolor and Striga hermonthica - The influence of soil organic matter amendments of different C:N ratio. Crop Prot. 30, $1613-1622$

Ayongwa, G. C., Stomph, T. J., Emechebe, A. M. \& Kuyper, T. W. 2006. Root nitrogen concentration of sorghum above 2\% produces least Striga hermonthica seed stimulation. Ann. Appl. Biol. 149, 255-262.

Bates, D., Mächler, M., Bolker, B. \& Walker, S. 2015. Fitting Linear Mixed-Effects Models Using lme4. 2015, $67,48$.

Blackshaw, R. E., Molnar, L. J. \& Larney, F. J. 2005. Fertiliser, manure and compost effects on weed growth and competition with winter wheat in western Canada. Crop Prot. 24, 971-980.

Bremner, J. M. \& Mulvaney, C. 1982. Nitrogen - total. Methods of soil analysis. Part 2. Chemical and microbiological properties, methodsofsoilan2), 595-624.

Cechin, I. \& Press, M. C. 1993. Nitrogen relations of the sorghum-Striga hermonthica host-parasite association: germination, attachment and early growth. New Phyt. 124, 681-687

Davies D. M., Graves J.D., 2000. The impact of phosphorus on interactions of the hemiparasitic angiosperm Rhinanthus minor and its host Lolium perenne. Oecologia 124, 100-106

Elliot, P., Clarisse, R., Beby, R. \& Josue, H. 1993. Weeds in rice in Madagascar. Int. Rice Res. Notes 18, 53-54.

Hansen, O. J. 1975. The genus Rhamphicarpa Benth. emend. Engl.(Scrophulariaceae): a taxonomic revision. Bot. Tidsskr. 70, 103-125.

Harrell Jr F.E., Dupont C., et al. 2019. Hmisc: Harrell Miscellaneous. R package version 4.3-0. https://CRAN.Rproject.org/package $=$ Hmisc

Hearne S.J., 2009. Control - the Striga conundrum. Pest Manage. Sci. 65, 603-614

Hothorn, T., Bretz, F. \& Westfall, P. 2008. Simultaneous inference in general parametric models. Biometrical J. $50,346-363$

Jamil, M., Charnikhova, T., Cardoso, C., Jamil, T., Ueno, K., Verstappen, F., Asami, T. \& Bouwmeester, H. J. 2011. Quantification of the relationship between strigolactones and Striga hermonthica infection in rice under varying levels of nitrogen and phosphorus. Weed Res. 51, 373-385

Jamil, M., Kanampiu, F. K., Karaya, H., Charnikhova, T. \& Bouwmeester, H. J. 2012. Striga hermonthica parasitism in maize in response to $\mathrm{N}$ and $\mathrm{P}$ fertilisers. Field Crop. Res. 134, 1-10

Johnson D.E., Riches C.R., Diallo R., Jones M.J. 1997. Striga on rice in West Africa; crop host range and the potential of host resistance. Crop Prot. 16, 153-157

Kabiri, S., Rodenburg, J., Kayeke, J., Van Ast, A., Makokha, D. W., Msangi, S. H., Irakiza, R. \& Bastiaans, L. 2015. Can the parasitic weeds Striga asiatica and Rhamphicarpa fistulosa co-occur in rain-fed rice? Weed Res. 55, 145-154

Kabiri S, van Ast A, Rodenburg J, Bastiaans L., 2016. Host influence on germination and reproduction of the facultative hemi-parasitic weed Rhamphicarpa fistulosa. Ann. Appl. Biol. 169, 144-154

Lenth, R. V. 2016. Least-squares means: the R package lsmeans. J. Stat. Softw. 69, 1-33.

McCullagh, P. \& Nelder, J. 1989. Generalised linear models II. London: Chapman and Hall.

Mehlich, A. 1984. Mehlich 3 soil test extractant: A modification of Mehlich 2 extractant. Comm. Soil Sci. Plan. $15,1409-1416$.

Mekuria W., Getnet K., Noble A., Hoanh C.T., McCartney M., Langan S., 2013. Economic valuation of organic and clay-based soil amendments in small-scale agriculture in Lao PDR. Field Crop. Res. 149, 379-389

N'cho S, Mourits, M, Rodenburg J, Demont M, Oude Lansink A. 2014. Determinants of parasitic weed infestation in rainfed lowland rice in Benin. Agr. Syst. 130, 105-115

Ouédraogo, O., Neumann, U., Raynal-Roques, A., Sallé, G., Tuquet, C. \& Dembélé, B. 1999. New insights concerning the ecology and the biology of Rhamphicarpa fistulosa (Scrophulariaceae). Weed Res. 39, 159-169.

Porteres, R., 1948. Plants indicating the fertility level of the edapho-climatic cultural complex in tropical Africa. Agron. Trop. 3, 246-257

Randrianjafizanaka M.T., Autfray P., Andrianaivo A.P., Ramonta I.R., Rodenburg J., 2018. Combined effects of cover crops, mulch, zero-tillage and resistant varieties on Striga asiatica (L.) Kuntze in rice-maize rotation systems. Agr. Ecosyst. Environ. 256, 23-33

R Core Team, 2019. R: A Language and Environment for Statistical Computing. R foundation for statistical computing, Vienna, Austria. https://www.R-project.org/.

Rodenburg J., Cissoko M., Kayongo N., Dieng I., Bisikwa J., Irakiza R., Masoka I., Midega C.A.O., Scholes J.D. 2017. Genetic variation and host-parasite specificity of Striga resistance and tolerance in rice: the need for predictive breeding. New Phyt. 214, 1267-1280

Rodenburg, J., Demont, M., Zwart, S. J. \& Bastiaans, L. 2016a. Parasitic weed incidence and related economic losses in rice in Africa. Agr. Ecosyst. Environ. 235, 306-317. 
Rodenburg, J., Cissoko, M., Dieng, I., Kayeke, J. \& Bastiaans, L. 2016b. Rice yields under Rhamphicarpa fistulosa-infested field conditions, and variety selection criteria for resistance and tolerance. Field Crop. Res. 194, 21-30.

Rodenburg, J. \& Johnson, D. 2009. Weed Management in Rice-Based Cropping Systems in Africa. Adv. Agron. $103,149-218$.

Rodenburg, J., Morawetz, J. J. \& Bastiaans, L. 2015. Rhamphicarpa fistulosa, a widespread facultative hemiparasitic weed, threatening rice production in Africa. Weed Res. 55, 118-131.

Rodenburg, J., Zossou-Kouderin, N., Gbèhounou, G., Ahanchede, A., Touré, A., Kyalo, G. \& Kiepe, P. 2011. Rhamphicarpa fistulosa, a parasitic weed threatening rain-fed lowland rice production in sub-Saharan Africa - A case study from Benin. Crop Prot. 30, 1306-1314.

Showemimo, F.A., C.A. Kimbeng, and S.O. Alabi, 2002. Genotypic response of sorghum cultivars to nitrogen fertilization in the control of Striga hermonthica. Crop Prot. 21, 867-870

Sokal, R. R. \& Rohlf, F. J. 1995. Biometry: the principles of statistics in biological research. New York, NY: WH Freeman and Co.

Tippe D, Rodenburg J, Schut M, van Ast A, Kayeke J, Bastiaans L. 2017a. Farmers' knowledge, use and preferences of parasitic weed management strategies in rain-fed rice production systems. Crop Prot. 99, 93-107

Tippe D, Rodenburg J, van Ast A, Anten NPR, Dieng I, Kayeke JM, Cissoko M, Bastiaans L. 2017b. Delayed or early sowing: timing as parasitic weed control strategy in rice is species and ecosystem dependent. Field Crop Res. 214, 14-24

Walkley, A. \& Black, I. A. 1934. An examination of the Degtjareff method for determining soil organic matter, and a proposed modification of the chromic acid titration method. Soil Sci. 37, 29-38.

Westwood, J. H., dePamphilis, C. W., Das, M., Fernández-Aparicio, M., Honaas, L. A., Timko, M. P., Wafula, E. K., Wickett, N. J. \& Yoder, J. I. 2011. The Parasitic Plant Genome Project: New Tools for Understanding the Biology of Orobanche and Striga. Weed Sci. 60, 295-306.

Zhao, Y.-N., He, X.-H., Huang, X.-C., Zhang, Y.-Q. \& Shi, X.-J. 2016. Increasing soil organic matter enhances inherent soil productivity while offsetting fertilization effect under a rice cropping system. Sustainability 8,879 . 


\section{Supplementary figures and tables}
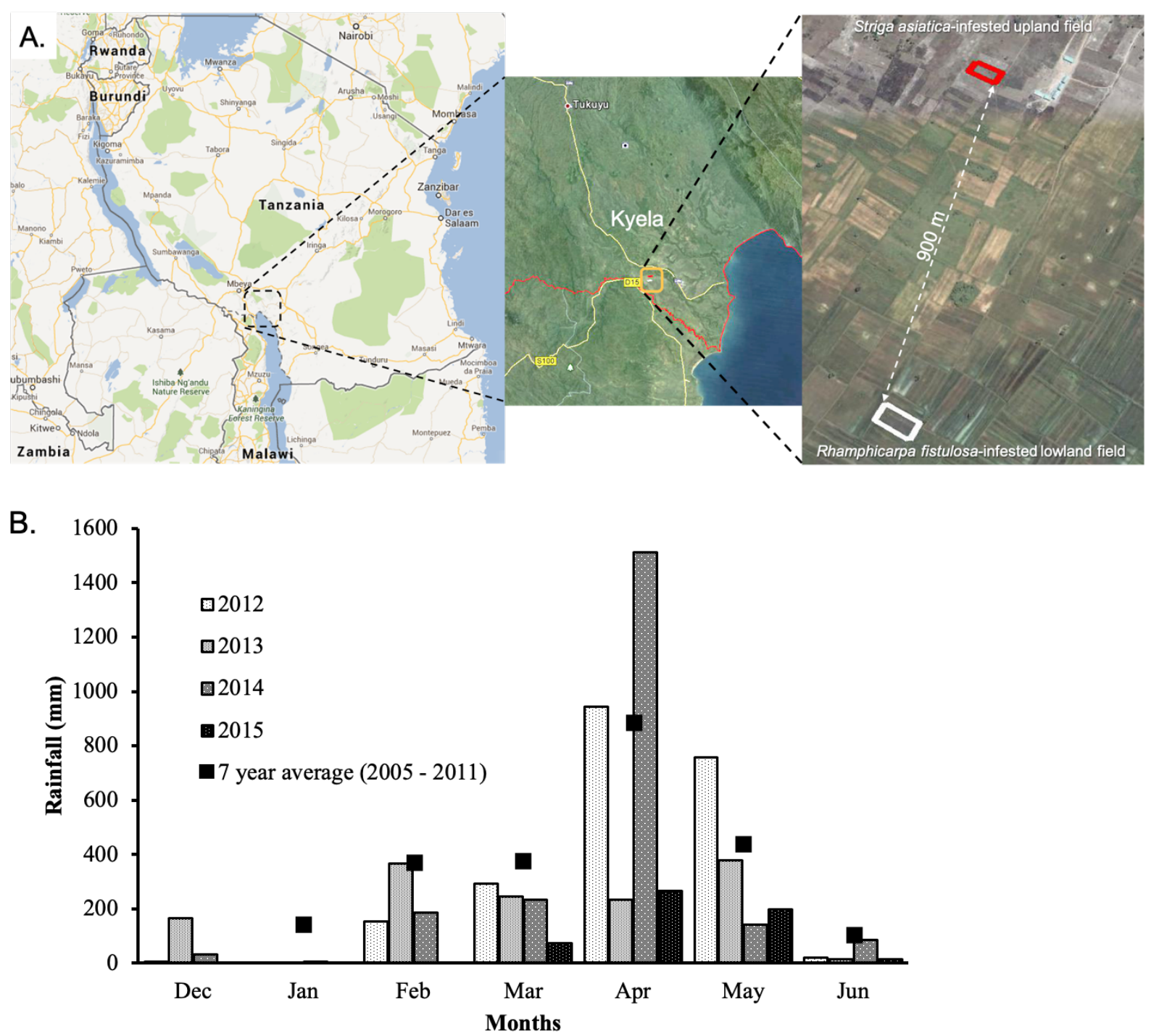

Figure S1. A. Geographical location of experimental fields, showing the distance between the Striga asiaticainfested upland field and the Rhamphicarpa fistulosa-infested lowland field (sources: Google Maps and Google Earth). B. Cumulative monthly rainfall ( $\mathrm{mm}$ ) as recorded in the experimental fields in Kyela district, Tanzania from December to June. For 2015, rainfall was not recorded prior to the start of the experiment (March). Additional data for the past 7 years prior to experimentation was received from Kyela District Agriculture and Livestock Office. 


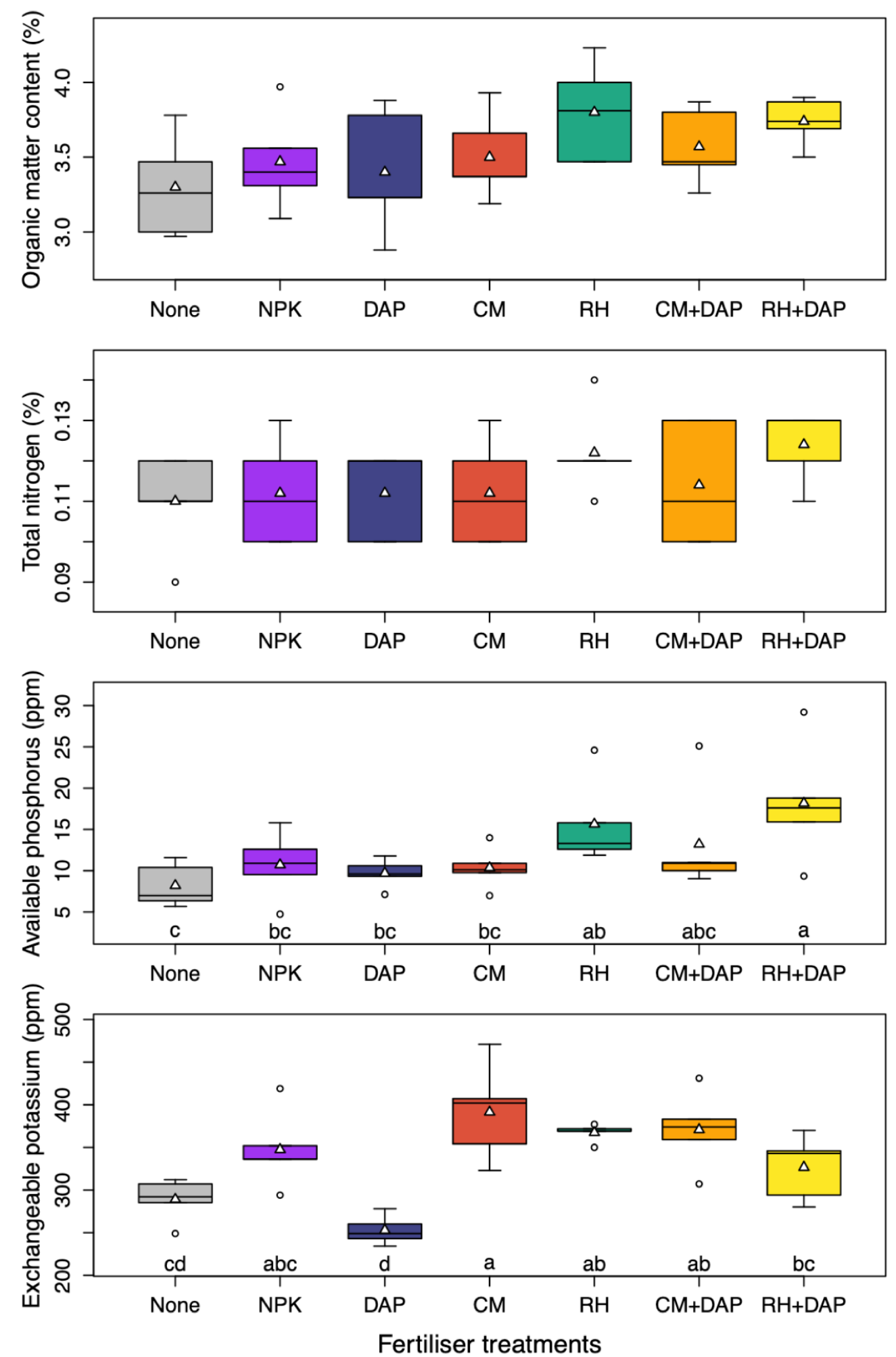

Figure S2. Soil fertility parameters from soil samples taken prior to sowing of the last season (March 2015) in the Striga asiatica-infested upland field following three seasons of fertiliser treatments. For each parameter, treatment means (indicated by white triangles) with the same letter are not significantly different according to Tukey's honest significant difference test $(P<0.05)$. No significant treatment effects were observed on organic matter content and total nitrogen. None $=$ no fertiliser; NPK $=$ mineral NPK fertiliser; DAP $=$ mineral DAP fertiliser plus urea; $\mathrm{CM}=$ Cattle manure; $\mathrm{RH}=$ Rice husks; $\mathrm{CM}+\mathrm{DAP}=$ Cattle manure and half rate of mineral $\mathrm{DAP}$ fertiliser plus urea; $\mathrm{RH}+\mathrm{DAP}=$ Rice husks and half rate of mineral DAP fertiliser plus urea. 

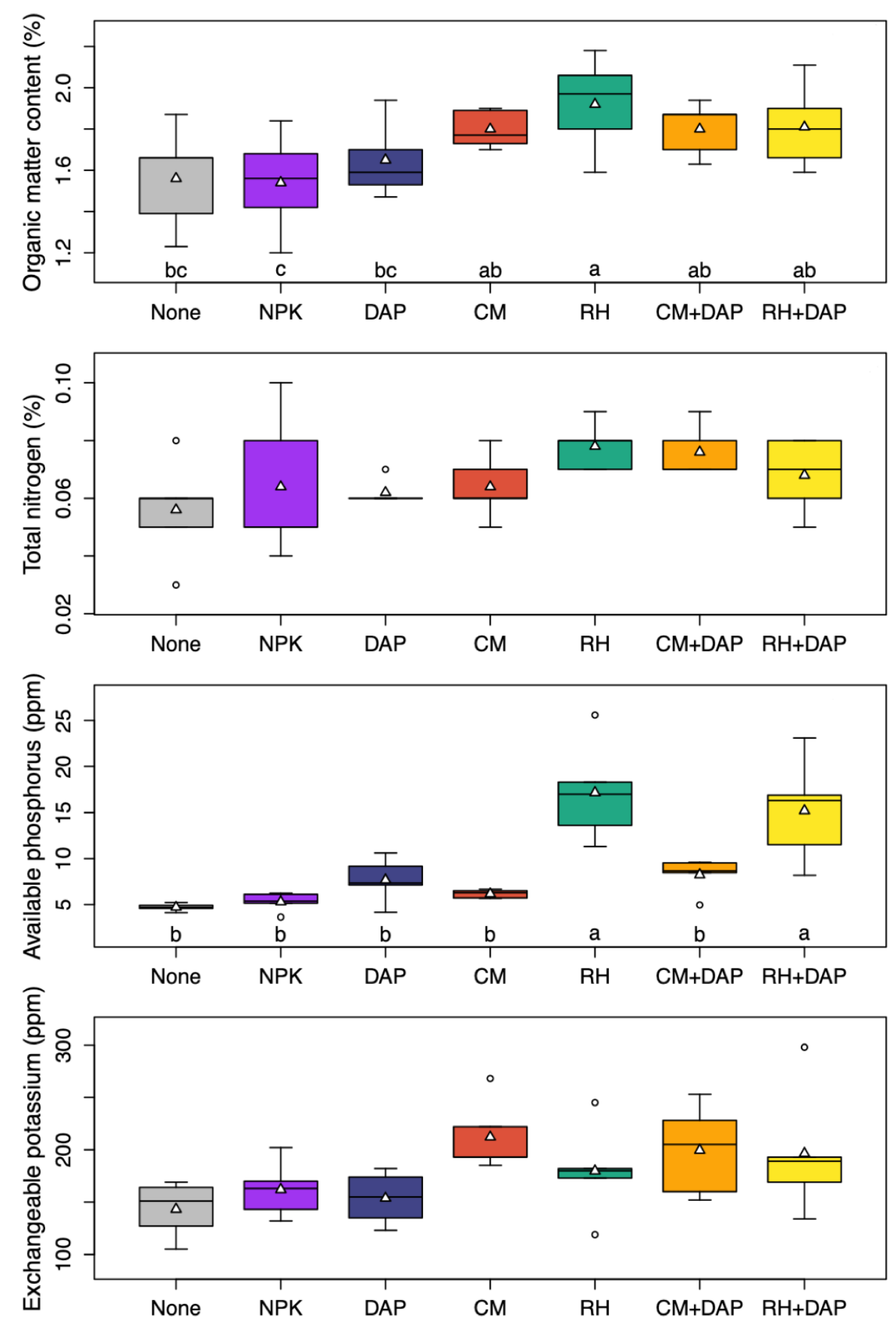

Fertiliser treatments

Figure S3. Soil fertility parameters from soil samples taken prior to sowing of the last season (March 2015) in the Rhamphicarpa fistulosa-infested lowland field following three seasons of fertiliser treatments. For each parameter, treatment means (indicated by white triangles) with the same letter) are not significantly different according to Tukey's honest significant difference test $(P<0.05)$. No significant treatment effects were observed on total nitrogen and exchangeable potassium. None $=$ no fertiliser; NPK= mineral NPK fertiliser; $\mathrm{DAP}=$ mineral DAP fertiliser plus urea; $\mathrm{CM}=$ Cattle manure; $\mathrm{RH}=$ Rice husks; $\mathrm{CM}+\mathrm{DAP}=$ Cattle manure and half rate of mineral DAP fertiliser plus urea; $\mathrm{RH}+\mathrm{DAP}=$ Rice husks and half rate of mineral DAP fertiliser plus urea. 
Table S1. Analysis of variance (ANOVA) and Tukey's honest significance difference test results ( $P$-values) of $S$. asiatica maximum number (NSmax; plants $\left.\mathrm{m}^{-2}\right), S$. asiatica above-ground dry weight $\left(S D W ; \mathrm{g} \mathrm{m}^{-2}\right)$, and rice grain yield $\left(G D W ; \mathrm{t} \mathrm{ha}^{-1}\right)$ as obtained from the rainfed upland rice field during four cropping seasons (2012-2015) in Kyela, Tanzania. Striga asiatica aboveground dry weight was only determined in the first two years of experimentation, due to the low infestation levels in the last two years. NSmax $S D W$

GDW

\begin{tabular}{|c|c|c|c|c|c|c|c|c|c|c|}
\hline Years & Source of variation & df & $\mathbf{F}$ & $\boldsymbol{P}$ & df & $\mathbf{F}$ & $\boldsymbol{P}$ & df & $\mathbf{F}$ & $\boldsymbol{P}$ \\
\hline \multirow[t]{3}{*}{$2012-15$} & Year $(\mathrm{Y})$ & 3 & 97.91 & $<0.0001$ & 1 & 17.28 & 0.0032 & 3 & 44.37 & $<0.0001$ \\
\hline & Fertiliser $(\mathrm{F})$ & 6 & 1.41 & 0.2186 & 6 & 0.83 & 0.5543 & 6 & 14.43 & $<0.0001$ \\
\hline & $\mathrm{Y} \times \mathrm{F}$ & 18 & 29.66 & $<0.0001$ & 6 & 2.64 & 0.0272 & 18 & 2.87 & 0.0005 \\
\hline \multicolumn{11}{|c|}{ Tukey's test } \\
\hline 2012 & $\mathrm{~F}$ & 6 & 57.35 & $<0.0001$ & 6 & 0.63 & 0.7028 & 6 & 1.22 & 0.3283 \\
\hline 2013 & $\mathrm{~F}$ & 6 & 54.88 & $<0.0001$ & 6 & 3.16 & 0.0198 & 6 & 0.58 & 0.7449 \\
\hline 2014 & $\mathrm{~F}$ & 6 & 4.42 & 0.0038 & & & & 6 & 10.7 & $<0.0001$ \\
\hline 2015 & $\mathrm{~F}$ & 6 & 0.2 & 0.9726 & & & & 6 & 13.04 & $<0.0001$ \\
\hline
\end{tabular}

Table S2. Analysis of variance (ANOVA) of $R$. fistulosa maximum plant number (NRmax; plants $\left.\mathrm{m}^{-2}\right), R$. fistulosa above-ground dry weight $\left(R D W\right.$; $\left.\mathrm{g} \mathrm{m}^{-2}\right)$, non-parasitic weed dry weight $\left(W D W ; \mathrm{g} \mathrm{m}^{-2}\right)$ and rice grain dry weight $\left(G D W ; \mathrm{t} \mathrm{ha}^{-1}\right)$ from the experimental rainfed lowland rice field during four cropping seasons in Kyela, Tanzania Significant $\mathrm{Y} \times \mathrm{F} \times \mathrm{W}$ interactions were followed by separate ANOVAs per year. Where the $\mathrm{Y} \times \mathrm{F} \times \mathrm{W}$ effects were not significant, Tukey's honest significance difference test results ( $P$-values) are provided for each year.

\begin{tabular}{|c|c|c|c|c|c|c|c|c|}
\hline \multirow[b]{2}{*}{ Years } & \multirow[b]{2}{*}{ Source of variation } & \multicolumn{3}{|c|}{$N R \max$} & \multicolumn{2}{|l|}{$R D W$} & \multicolumn{2}{|l|}{$G D W$} \\
\hline & & df & $\mathbf{F}$ & $\boldsymbol{P}$ & $\mathbf{F}$ & $P$ & $\mathbf{F}$ & $P$ \\
\hline \multirow[t]{3}{*}{$2012-15$} & Year $(Y)$ & 3 & 156.35 & $<0.0001$ & 154.11 & $<0.0001$ & 186.1 & $<0.0001$ \\
\hline & Fertiliser $(\mathrm{F})$ & 6 & 58.31 & $<0.0001$ & 8.67 & $<0.0001$ & 46.04 & $<0.0001$ \\
\hline & $\mathrm{Y} \times \mathrm{F}$ & 18 & 11.26 & $<0.0001$ & 5.69 & $<0.0001$ & 5.75 & $<0.0001$ \\
\hline Tukey's test & & & & & & & & \\
\hline 2012 & $\mathrm{~F}$ & 6 & 160.69 & $<0.0001$ & 9.15 & $<0.0001$ & 8.51 & $<0.0001$ \\
\hline 2013 & $\mathrm{~F}$ & 6 & 8.95 & $<0.0001$ & 1.01 & 0.4431 & 20.3 & $<0.0001$ \\
\hline 2014 & $\mathrm{~F}$ & 6 & 18.39 & $<0.0001$ & 1.67 & 0.1716 & 14.04 & $<0.0001$ \\
\hline 2015 & $\mathrm{~F}$ & 6 & 5.42 & 0.0012 & 5.67 & 0.0009 & 18.4 & $<0.0001$ \\
\hline
\end{tabular}




\section{Field Crops Research}

Table S3. Analysis of variance (ANOVA) of soil fertility parameters ( $\left.\mathrm{N}_{\text {Total }}, \mathrm{P}_{\text {Avaialble, }}, \mathrm{K}_{\text {exchangeable, }} \mathrm{SOM}, \mathrm{pH}\right)$ of the upland and lowland field prior to the last experimental season in Kyela, Tanzania.

\begin{tabular}{|c|c|c|c|c|c|c|c|c|c|c|c|}
\hline \multirow[b]{2}{*}{ Source of variation } & \multicolumn{3}{|c|}{$\mathbf{N}_{\text {Total }}$} & \multicolumn{2}{|c|}{$\mathbf{P}_{\text {Available }}$} & \multicolumn{2}{|c|}{ KExchangeable } & \multirow{2}{*}{$\begin{array}{l}\text { SOM } \\
\text { F }\end{array}$} & \multicolumn{3}{|c|}{ pH } \\
\hline & df & $\mathrm{F}$ & $P$ & $\mathrm{~F}$ & $P$ & $\mathrm{~F}$ & $P$ & & $P$ & $\mathrm{~F}$ & $P$ \\
\hline Fertiliser - upland & 6 & 1.03 & 0.4329 & 3.0 & 0.0247 & 12.08 & $<0.001$ & 1.8 & 0.1423 & 9.75 & $<0.001$ \\
\hline Fertiliser - lowland & 6 & 1.59 & 0.1941 & 11.72 & $<0.001$ & 2.30 & 0.0679 & 2.64 & 0.0411 & 2.21 & 0.0778 \\
\hline
\end{tabular}

Tabel S4. Pearson correlation coefficients between soil fertility parameters from soil samples taken prior to sowing of the last season (March 2015) and parasite numbers (NSmax for Striga; NRmax for Rhamphicarpa) and rice grain yield (GDW) of the 2015 and 2004 crop season

\begin{tabular}{|c|c|c|c|c|}
\hline Upland soil parameters & NSmax_2014 & NSmax_2015 & GDW_2014 & GDW_2015 \\
\hline Pavailable & 0.058 & 0.216 & 0.283 & $0.498 * *$ \\
\hline SOM & -0.181 & -0.072 & $0.609 * * *$ & $0.558 * * *$ \\
\hline Lowland soil parameters & NRmax_2014 & NRmax_2015 & GDW_2014 & GDW_2015 \\
\hline $\mathrm{P}_{\text {available }}$ & $0.526^{* *}$ & 0.054 & $0.340^{*}$ & $0.428^{*}$ \\
\hline Kexchangeable & $0.586 * * *$ & 0.232 & 0.235 & 0.037 \\
\hline $\mathrm{P}<0.001$ & $\mathrm{P}<0.01$ & $\mathrm{P}<0.05$ & - & \\
\hline
\end{tabular}

